\title{
A depth-integrated SPH model for debris floods: application to Lo Wai (Hong Kong) debris flood of August 2005
}

\author{
CHUAN LIN*, MANUEL PASTOR $\uparrow$, ANGEL YAGUE $\uparrow$, SAEID MOUSSAVI TAYYEBI†, \\ MIGUEL MARTIN STICKLE ${ }^{\S}$, DIEGO MANZANAL $\uparrow \|$, TONGCHUN LI $\uparrow$ and XIAOQING LIU**
}

\begin{abstract}
In this work an approach to representing debris floods and flows is proposed, based on a depthintegrated mathematical model and smooth particle hydrodynamics numerical technique. The main contributions of the present work are twofold: $(a)$ an improved rheological Bingham model where solid fraction concentration can change as solids are entrained by the current and $(b)$ implementation of boundary conditions describing the injection process of water from channel weirs into the domain. The model has been applied to the case of Lo Wai debris flood (Hong Kong, August 2005). Numerical results obtained with the proposed model are in reasonable agreement with field observation.
\end{abstract}

KEYWORDS: landslides; numerical modelling; water flow

\section{INTRODUCTION}

Landslides are natural disasters responsible for loss of life and serious economic damage around the world. There are many alternative classifications of landslides. Dikau et al. (1996) consider two types: slides and flows. From a geotechnical point of view, the failure mechanisms of slides are of a localised type, while flows are in many cases of diffuse type.

Landslides are of major concern in Hong Kong, where the population density is very high, rain can be intense and steep slopes abound. In fact, only $40 \%$ of the land can be considered flat, and the average number of landslides per year is close to 300 (Ho et al., 2009).

During recent decades, many catastrophic landslides have occurred, such as those of Sau Mau Ping in 1972 and 1976. In 1972 , after intense rain, $6000 \mathrm{~m}^{3}$ of fill material from a road embankment collapsed, flowing downhill 'as a carpet'. It was reported that the fill material was deposited by end tipping, which caused a loose, metastable structure wherein the failure mechanism is often of diffuse type. In 1976, the rain brought by the tropical cyclone Ellen caused a second

Manuscript received 25 October 2017; revised manuscript accepted 20 December 2018. Published online ahead of print 14 February 2019.

Discussion on this paper closes on 1 May 2020, for further details see p. ii.

*ollege of Water Conservancy and Hydropower, Hohai University, Nanjing, P. R. China (Orcid:0000-0001-6109-5777).

$\dagger$ Department of Applied Mathematics, ETSI Caminos, Universidad Politécnica de Madrid, Madrid, Spain

(Orcid:0000-0002-6087-3255).

+ Department of Applied Mathematics, ETSI Caminos, Universidad Politécnica de Madrid, Madrid, Spain

(Orcid:0000-0002-3290-9433).

$\S$ Department of Applied Mathematics, ETSI Caminos,

Universidad Politécnica de Madrid, Madrid, Spain

(Orcid:0000-0001-7591-418X).

|| INTECIN-CONICET-UBA-UNPSJB, Buenos Aires, Argentina

(Orcid:0000-0002-6087-3255).

- National Engineering Research Center of Water Resource Efficient Utilization and Engineering Safety, Nanjing, P. R. China; College of Water Conservancy and Hydropower, Hohai University, Nanjing, P. R. China.

** College of Water Conservancy and Hydropower, Hohai University, Nanjing, P. R. China. landslide at the same location, accompanied by three other landslides resulting from the collapse of side slopes of highway embankments. In the three cases, the landslides evolved into mudslides.

To a series of representative landslides, which in some cases turned into flows - Baguio Villas (1992), Tsing Shan (1990, 2000), Tseng San Tsuen (1999) - can be added Lo Wai landslide in 2005. These landslides of flow type are often channelised by narrow valleys, where both bottom and lateral erosion occur. Bloor (2011: p. 4) presented a most interesting analysis of rock avalanches, debris flows and floods that occurred in Hong Kong in 2008, affecting Lantau island, Hong Kong and the village of Wang Han. He concluded that the largest events were debris floods, and therefore 'mitigation strategies can be rethought in order to accommodate the large volumes of water which run off from the hillside catchments as well as mitigate against debris-flow events which have continued through to 2008 and which are capable of becoming channelised and occurring again in the future'.

Two of the most common types of landslides in Hong Kong are debris flows and debris floods; the former occur more frequently. In some cases, the origin of these flows is related to the combination of solid materials provided by shallow landslides and runoff water, whereas in others, water flowing along steep channels entrains solid materials, both from the bottom and from the side slopes of the channel.

Debris flows and floods can be defined, respectively, as follows.

(a) Gravitational flows of saturated materials with solid volume fraction above $60 \%$. Their behaviour depends on their composition. They can behave as cohesive-frictional materials presenting viscosity. The components vary: mud, silt, sands, rocks, boulders and even logs or fallen trees.

(b) Debris floods, also referred to as hyperconcentrated flows, can be considered as intermediate states between water and debris flows, where the volume fraction of the solid content is in the range of $20-60 \%$.

It is important to note that debris floods can evolve into debris flows. This is precisely the case in Lo Wai, which is studied in the present work. A catchwater channelling rain water was blocked, the water flowing through weirs into 
natural channels that were severely eroded. As erosion was taking place, the flow changed from debris flood to debris flow, its rheological properties changing with the amount of entrained solids.

Debris flows and floods have been described by Hutchinson (1988), Costa (1988), Pierson \& Costa (1987) and Hungr (2005). Recent cases of debris floods have been studied by Yumuang (2006), Chen et al. (2018) and Li et al. (2017) in Thailand, Taiwan and China, respectively.

Modelling of these phenomena is of paramount importance to geotechnical engineers, geologists and urban planners concerned with assessing their risk (Cheong, 1991). Because three-dimensional models are computationally expensive, depth-integrated models are frequently used in a wide range of geotechnical problems, as they provide a reasonable compromise between cost and accuracy. This approach has been used by researchers to model debris floods (Chen et al., 2018; Li et al., 2017). Chen et al. (2018) studied debris floods in Taiwan using an unsteady two-dimensional (2D) depth-averaged model. The equations were discretised using an Eulerian grid. Li et al. (2017) have used an Eulerian depth integrated model for hyperconcentrated flows which has been discretised using a cell-centred finite-volume scheme. Basal friction was assumed to be of Manning type.

Regarding basal erosion, it plays an important role in debris flow propagation, as debris flow volumes can increase significantly (Hungr et al., 2005; Iverson et al., 2005; Pirulli \& Pastor, 2012; Frank et al., 2017).

Rheological modelling is a key ingredient in the analysis. Debris floods and flows are mixtures of solid particles and fluids, with a complex behaviour exhibiting cohesion, friction and viscosity, which depend on the volume concentration of solid particles (O'Brien \& Julien, 1988; Rickenmann, 1991; O’Brien et al., 1993; De Campos \& Galindo, 2016).

It is worth mentioning the interest of the Hong Kong Administration - the Hong Kong Geotechnical Office - on promoting the development of accurate models. In fact, in 2007, they organised a modelling activity where researchers were asked to model a set of 12 tests, including problems with an analytical solution, laboratory tests, small run-out landslides, debris flows and debris floods, the latter being that of Lo Wai (August 2005). This test case was considered the most complex.

The current paper presents a depth-integrated smooth particle hydrodynamics (SPH) model that is able to reproduce Lo Wai debris flood. It is based on the interpretation of the phenomena described in the report of Maunsell Geotechnical Services Limited (MGS, 2006). According to this report, the flood was caused by two small landslides which blocked a catchwater channel collecting the runoff water. Water entered two limbs of a natural channel through two weirs. Because of the steep slope of the channel, erosion was very important and a large amount of solid particles was entrained. In the current authors' opinion, the three main features of Lo Wai debris flood were the water overflow in the weirs, the entrainment of solid materials and the change of the rheological properties of the fluid with the increase of solid fraction. To account for these, the current authors have proposed

(a) an improved Bingham model with yield stress and viscosity dependent on solid particles concentration

(b) a new type of boundary conditions describing the injection process of water from the channel weirs into the domain.

The paper is structured as follows. In the next section, the Lo Wai case is summarised, including site description and modelling. Modelling details of practical importance are given, paying special attention to the injection of water particles into the domain. Then the improved Bingham model is presented in order to reproduce the rheological behaviour. Finally, a description of the results obtained, employing the proposed model, is provided and some conclusions are established. The mathematical and numerical models used in the analysis are outlined in the Appendix.

\section{DESCRIPTION OF LO WAI SITE}

Lo Wai is located in Sha Tin district, $2 \mathrm{~km}$ south of Tai Mo Shan massif, and belongs to the Hong Kong New Territories. Fig. 1 presents a map in which the main topographic features are depicted; an aerial view is provided in Fig. 2. It can be seen here that the Shing Mung catchwater runs east to west, with the controlled intake dam at chainage M3078; the position where the slope number 7SW-A/CR134 blocked the channel can also be seen.

The most relevant features are listed below.

(a) A catchwater located $500 \mathrm{~m}$ above Lo Wai village collects runoff water by intercepting natural stream courses running down Tai Mo Shan. The catchwater has a trapezoidal section with a height of $3 \cdot 2 \mathrm{~m}$, the upper and the lower widths being 6 and $3.3 \mathrm{~m}$, respectively. Its slope is approximately $1.7 \times 10^{-3}$ and the maximum capacity is $7 \cdot 8 \mathrm{~m}^{3} / \mathrm{s}$. A road is located at the side of the catchwater, providing service to it.

(b) The catchwater is provided with overflow weirs, located at natural stream courses. The positions of the two overflow weirs relevant to this analysis, SMOF-12 and SMOF-13, are shown. Their dimensions are $9 \mathrm{~m}$ wide and $0.6 \mathrm{~m}$ high (Fig. 3). Their purpose is to evacuate excess water from the channel, preventing the water from escaping at locations where the damage it could cause would be greater. In this way, water will flow from the weirs to the better-protected stream courses.

(c) The most relevant stream courses to be considered in this case are referred to as the southwest and west limbs; they have widths close to $4 \mathrm{~m}$, and join the main stream course after running downhill some $60 \mathrm{~m}$. Their slopes range from $36^{\circ}$ at the upper zone to $9 \cdot 5^{\circ}$ close to the confluence. From there, the main course runs southwest. The average slope is $9^{\circ}$; its end is connected to a $600 \mathrm{~mm}$ dia. underground drainage pipe. In the close neighbourhood of the main stream there are a surface car park, and two temples, the Yuen Yuen Institute and the Western monastery. Fig. 4 shows longitudinal sections of the stream course before and after the event. The figure provides schematic information regarding the profiles of the path followed by the water and debris flood along the southwest and west limbs. The horizontal scale shows the distance along the path. This distance identifies the position of particular places. For instance, Ch. 226 refers to a point located $226 \mathrm{~m}$ downhill. In the figure it is possible to observe how erosion was more important from the weirs to a point located $174 \mathrm{~m}$ downstream. Debris deposits are more important at points 215 and 330, with depths of 1.5 and $2.0 \mathrm{~m}$, approximately.

(d) Slopes are given a reference number. For instance, slope 7SW-A/CR134, which is $50 \mathrm{~m}$ wide, is located just above the catchwater (Fig. 5). Slopes 7SW-A/F76 and 7SW-A/F77 are located at the sides of the natural stream. The former is $80 \mathrm{~m}$ long and $4 \mathrm{~m}$ high with an inclination of $35^{\circ}$, while the latter is $168 \mathrm{~m}$ long and $5 \mathrm{~m}$ high with an inclination of $35^{\circ}$. At the crests there 


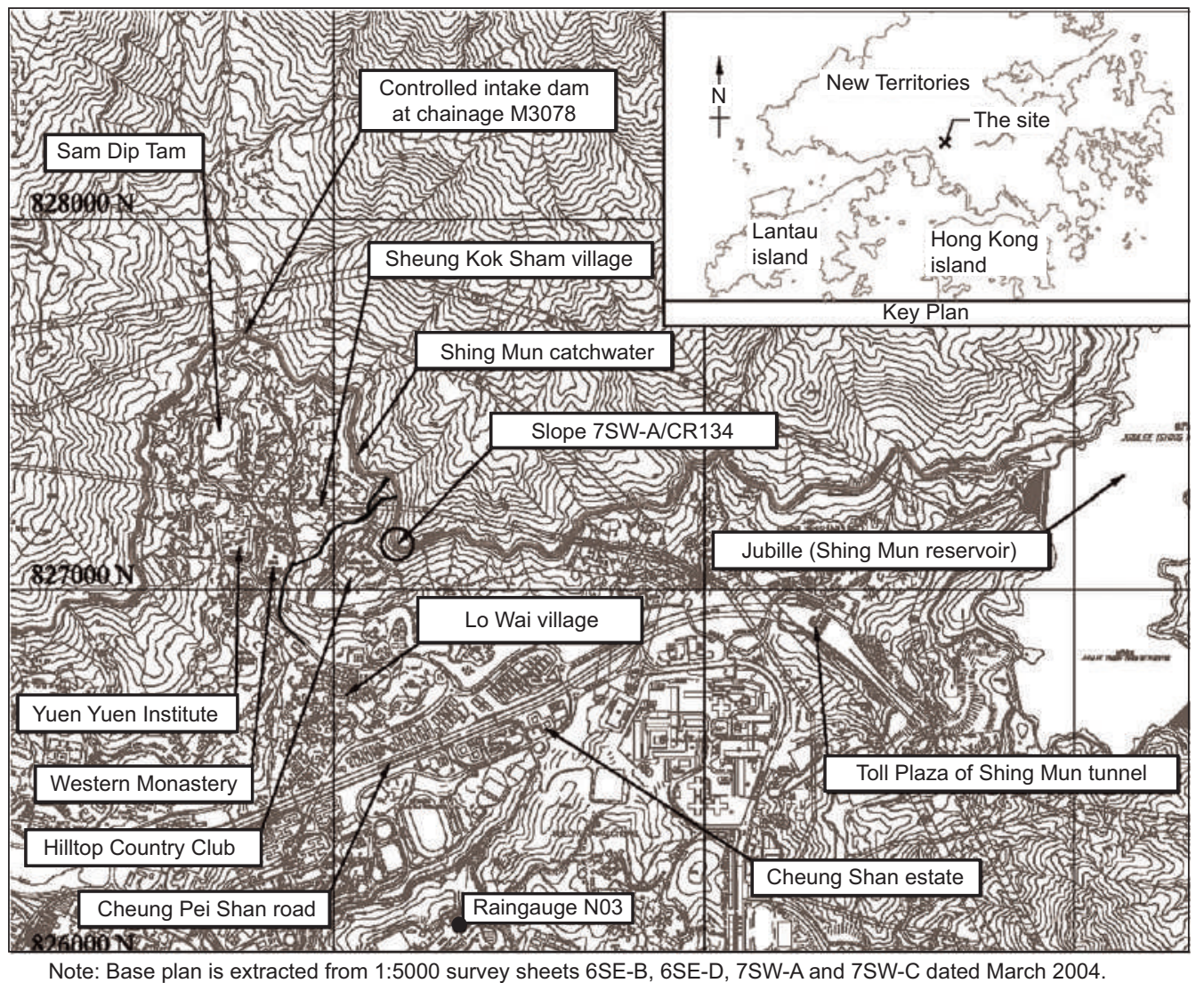

Fig. 1. General location map (Maunsell Geotechnical Services Limited (MGS, 2006))

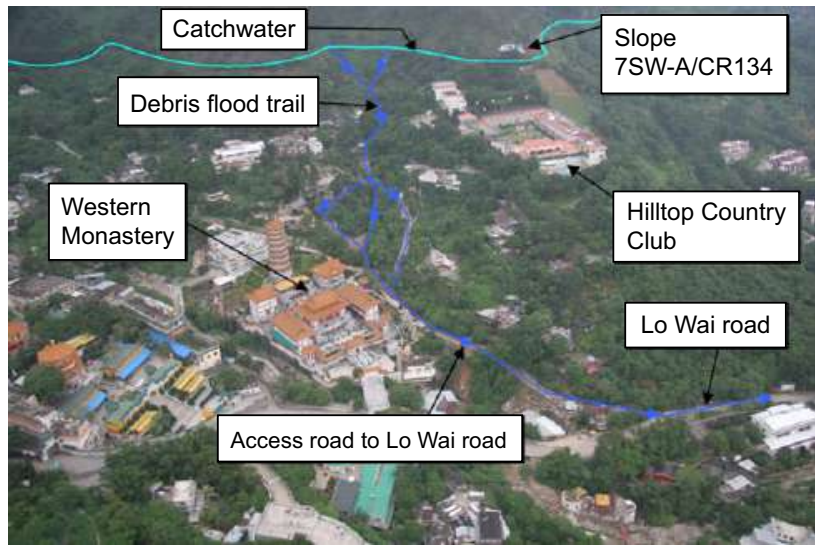

Fig. 2. Oblique aerial view of the debris flood trail (Maunsell Geotechnical Services Limited (MGS, 2006)) (photograph taken on 22 August 2005)

are small houses. Both slopes are erodible. Indeed, severe erosion took place at the southwest and west limbs during the period 1945-1963, resulting in steeper side slopes. Fig. 5 presents the scar left by the landslide which blocked the channel. The figure provides information on the different soils found in the slope. The soils are labelled as MT1, 2, 3 and 4.

(e) Access and Lo Wai roads.

The lower paths followed by the flood were the access road from Lo Wai and the Lo Wai road. The former is $330 \mathrm{~m}$ long and $4 \mathrm{~m}$ wide, running from the open car park to Lo Wai village, with a slope of $7^{\circ}$. It connects to Lo Wai road, which is a two-lane, $7 \mathrm{~m}$ wide road (Figs 2 and 6).

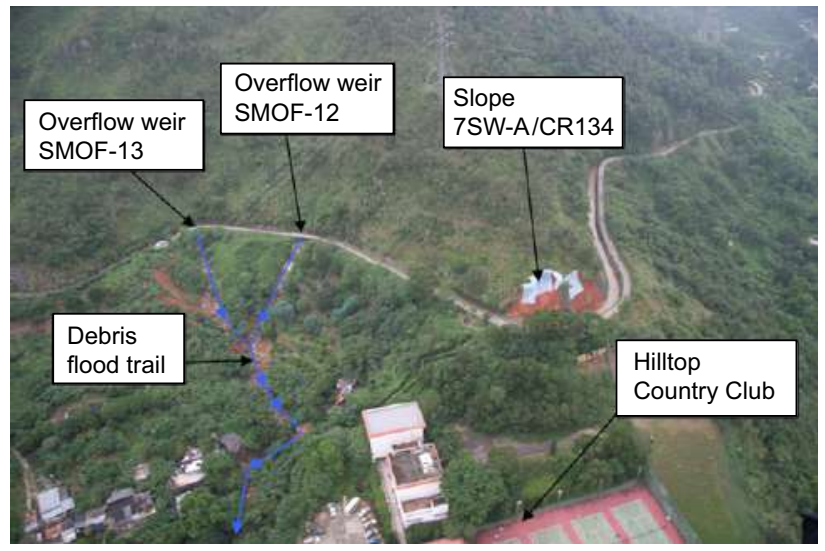

Fig. 3. Aerial view of the catchwater with overflow weirs MOF-13 and 12, together with the location where the landslide on slope 7SW-A/CR134 blocked the channel (Maunsell Geotechnical Services Limited (MGS, 2006))

\section{THE LO WAI DEBRIS FLOOD AND FLOW OF} AUGUST 2005: DESCRIPTION AND MODELLING Description of the event

Lo Wai debris flood and debris flow were caused by intensive rain between 4.15 and 5.00 p.m. on 20 August 2005. The landslide and rainstorm warnings had been activated more than $19 \mathrm{~h}$ before. Two landslides were triggered on slope 7SW-A/CR134, blocking the catchwater. Fig. 5 shows the landslide scar.

The water started flowing through the overflow weirs SMOF-12 and SMOF-13 and into the two limbs of the natural stream course. Fig. 2 provides a general view of the debris flood path, with the location of the two landslides, and 

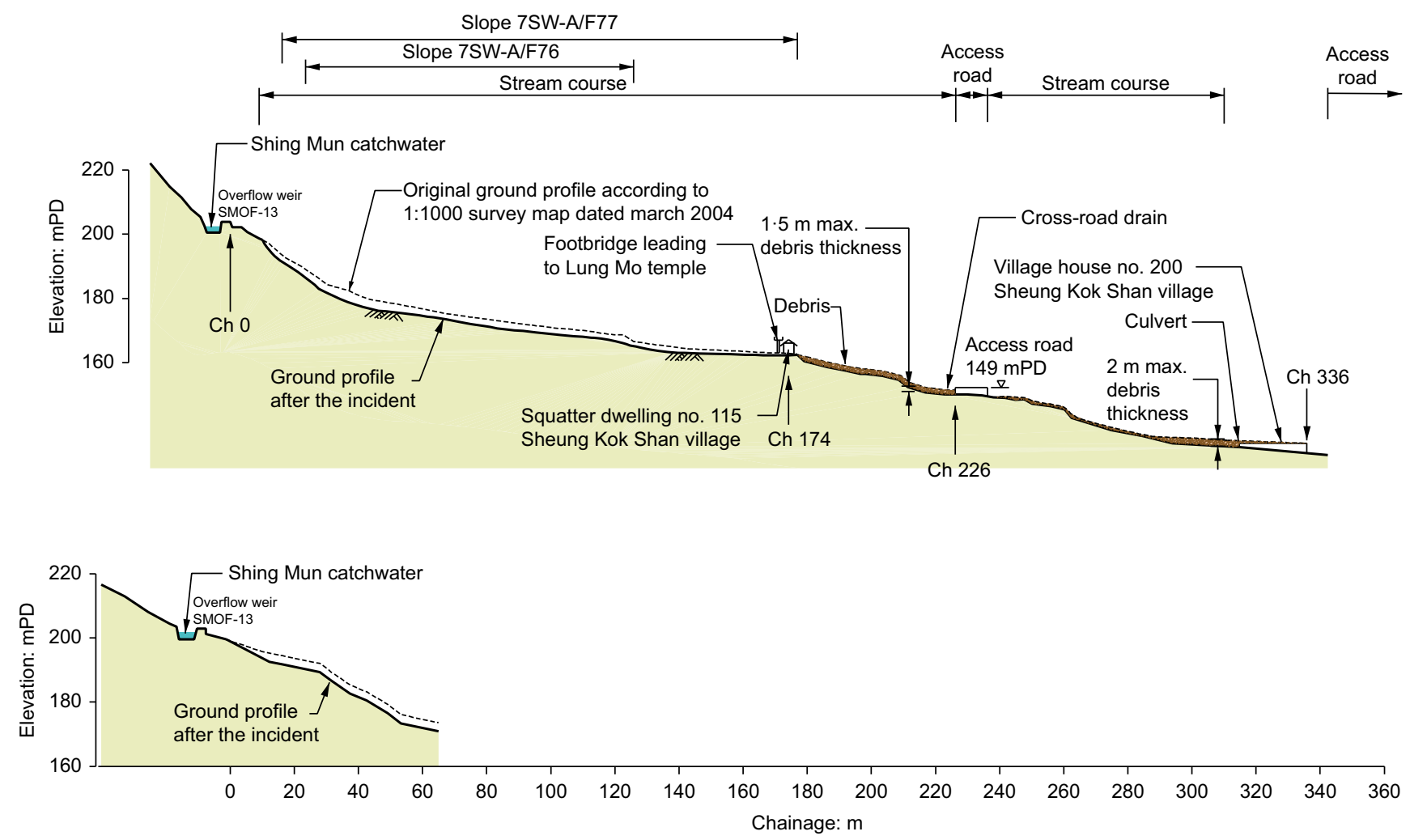

Fig. 4. Longitudinal section of stream course (Maunsell Geotechnical Services Limited (MGS, 2006))

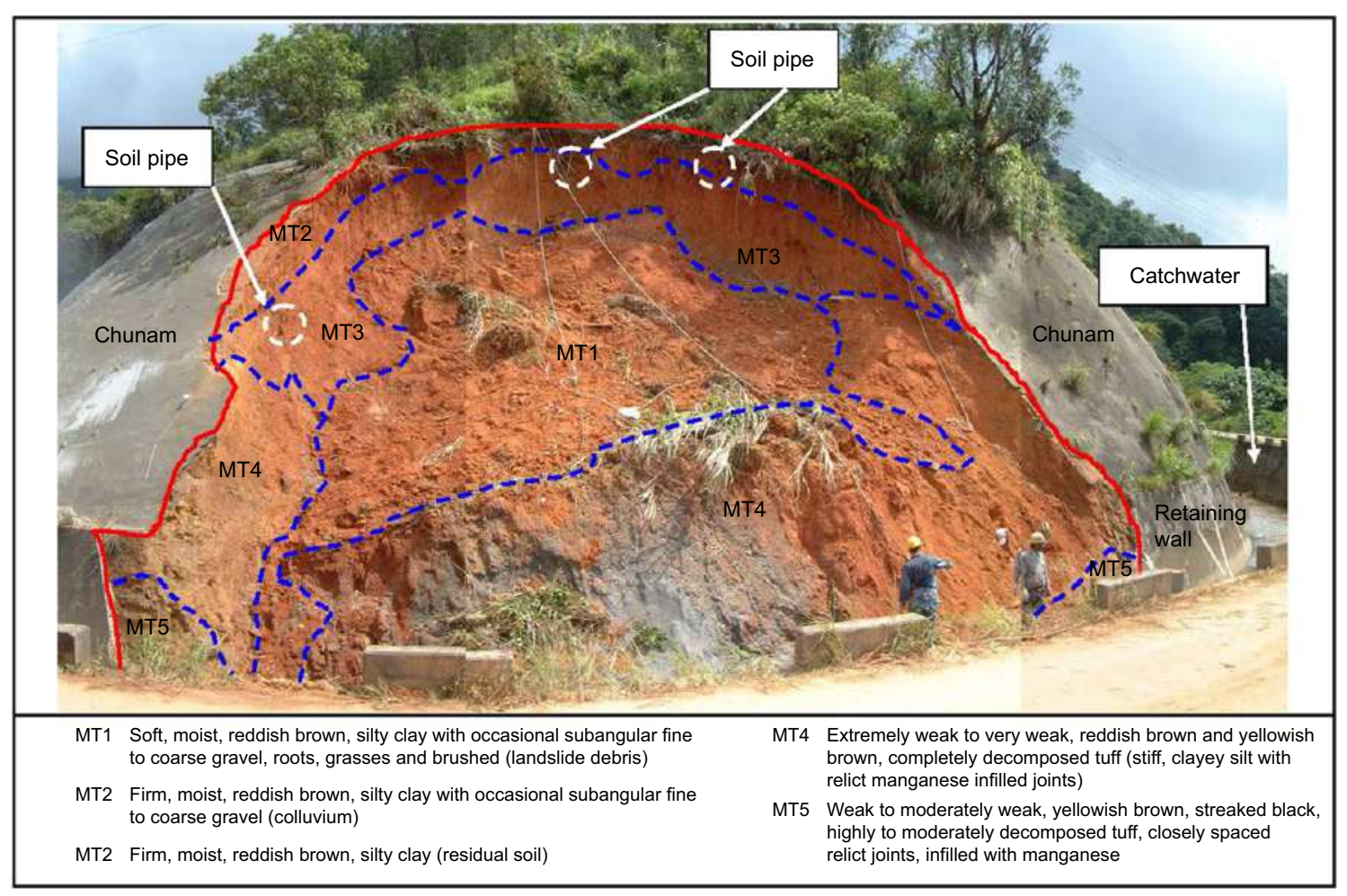

Fig. 5. Field mapping of landslide scar a at slope 7SW-A/CR134 (Maunsell Geotechnical Services Limited (MGS, 2006))

Fig. 3 provides a more detailed view of the weirs. The debris flood trail is depicted in Fig. 7, showing the location of the catchwater, the two weirs, the stream courses and the path along the roads. Important features displayed here are the southwest and west limbs, with the cut, which will be used later to describe their erosion, and the slopes labelled 7SW-A/F77 and 76.

The longitudinal section of the stream course was given in Fig. 4 from the overflow weirs to Lo Wai. As the water flowed through the natural streams, it eroded both their bottom and 


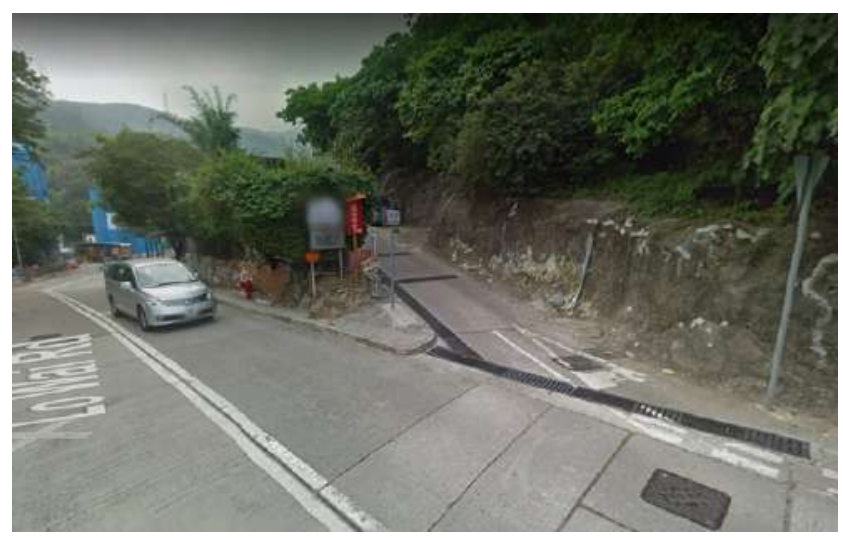

Fig. 6. The intersection of the access road with Lo Wai road sides, entraining solid materials into the current. Figs 8 and 9 provide information on the erosion that affected the two limbs of the stream course. Section $\mathrm{X}-\mathrm{X}$ is located at position $\mathrm{CH} 42$ (see Figs 4 and 7). There, erosion was intense, the basal surface being eroded $3 \mathrm{~m}$.

Figure 8 presents a section of the two limbs, the materials being described as colluvium and young colluvium. Boulders exist under the colluvium layers and at the bottom of the stream courses. As the lateral slopes are steep (see Fig. 9), shallow landslides were triggered, providing additional solid material to the channel.

Intense erosion also took place at slopes 7SW-A/F76 and 77 , providing additional solid materials. Fig. 10 provides a photograph of the main stream course and the slopes. The location of the slopes is provided in Fig. 7.

As a consequence, the solid fraction was increasing, and the flow developed into a debris flood. The rheological properties changed, evolving into a viscous-cohesive fluid.

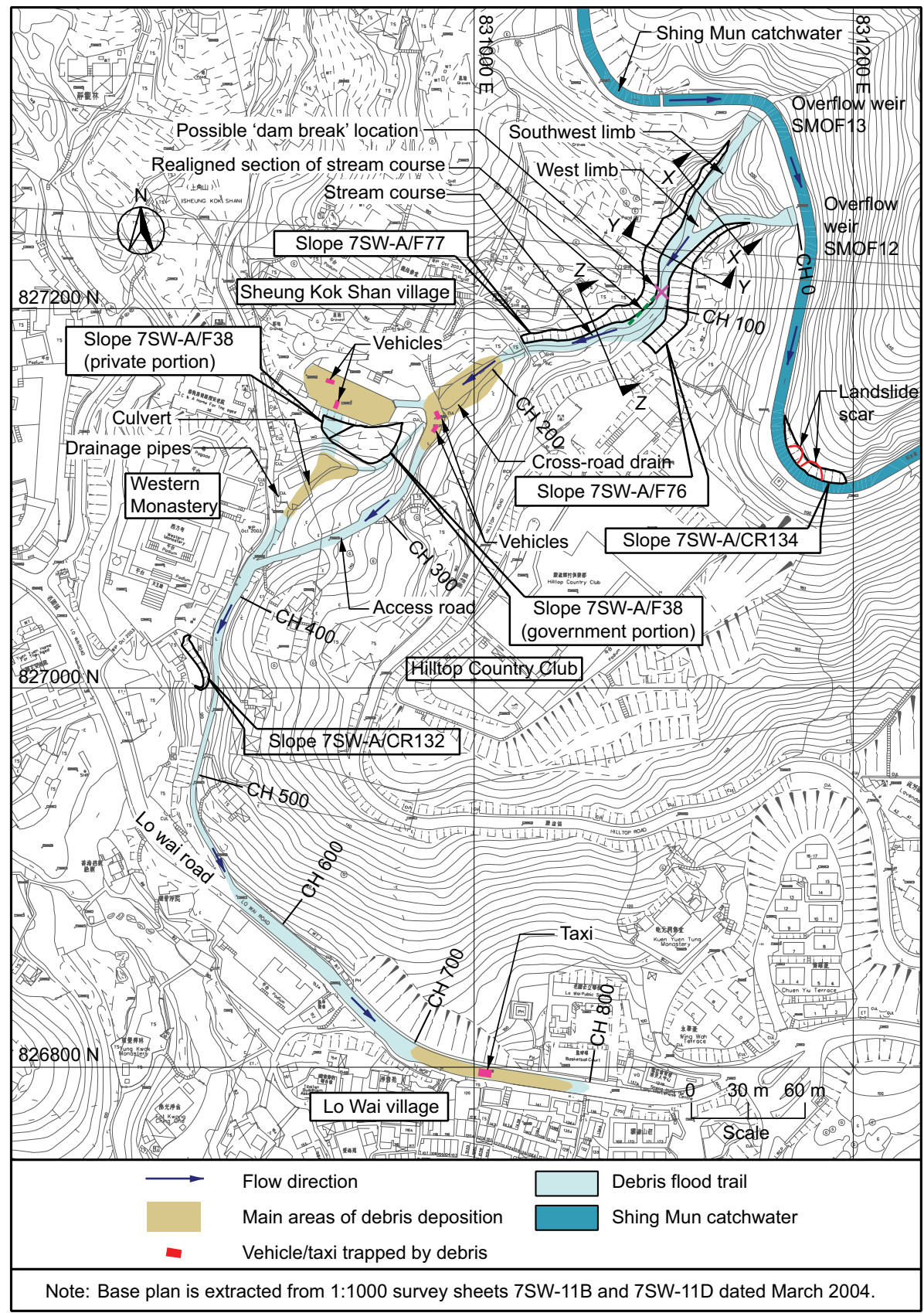

Fig. 7. Debris flood trail (Maunsell Geotechnical Services Limited (MGS, 2006)) 


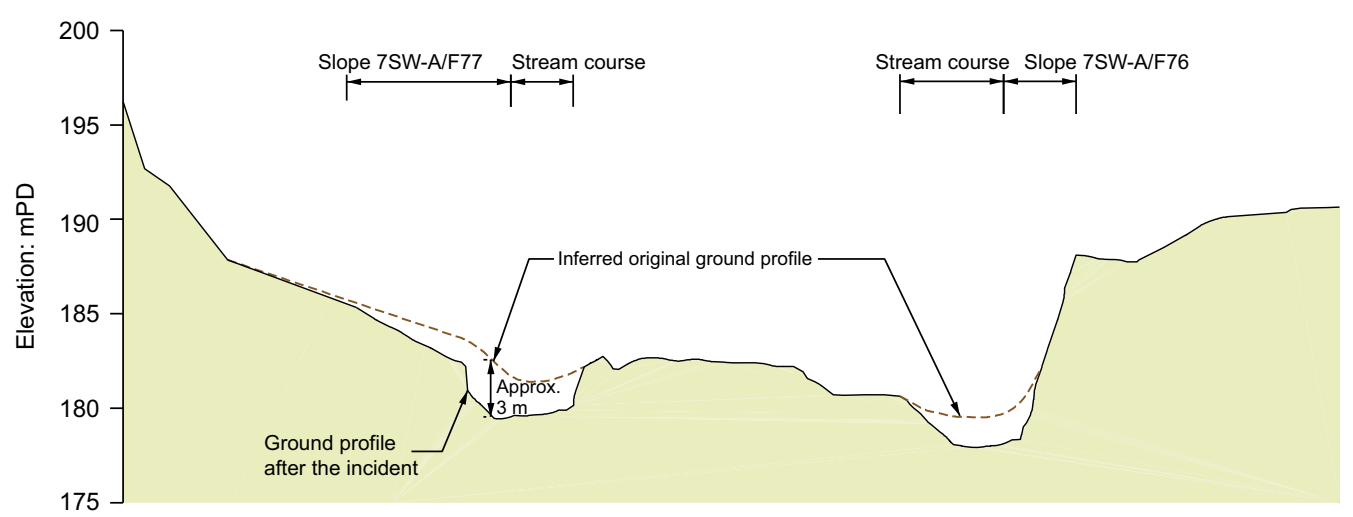

Fig. 8. Cross-section X-X at approximate chainage CH 42 before and after 20 August 2005 incident (Maunsell Geotechnical Services Limited (MGS, 2006))
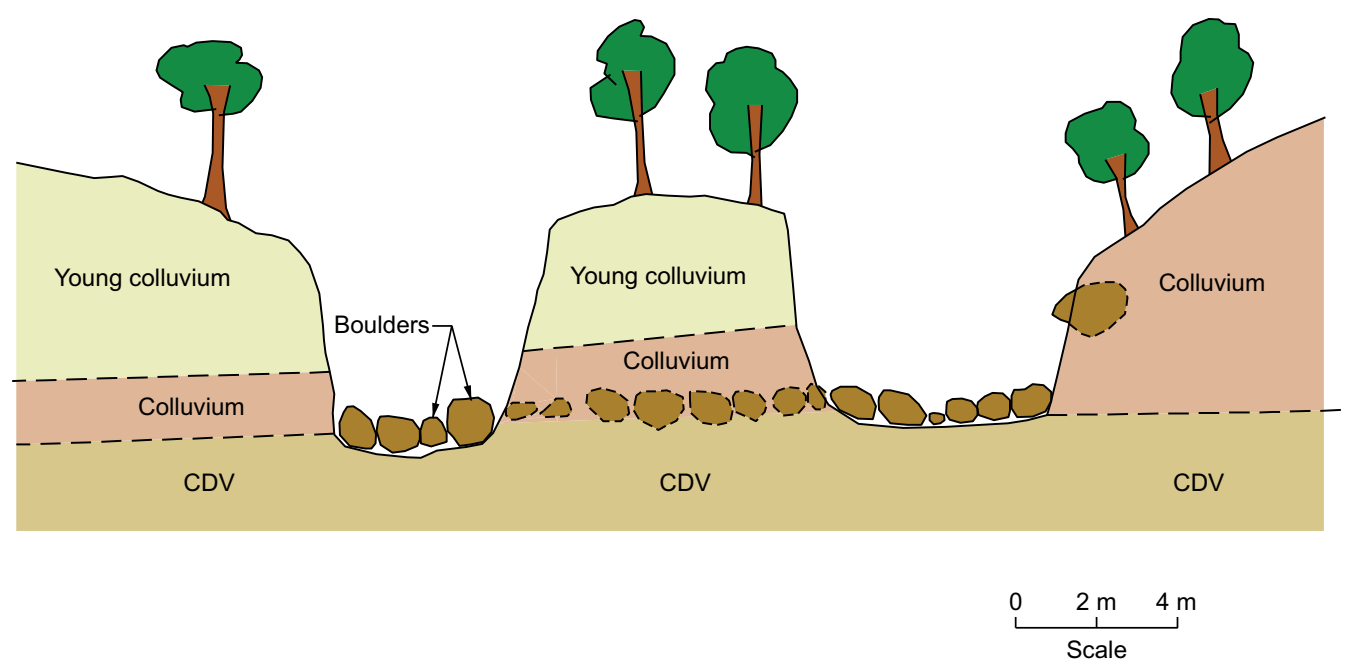

Fig. 9. Geological section of two limbs of stream course (Maunsell Geotechnical Services Limited (MGS, 2006))

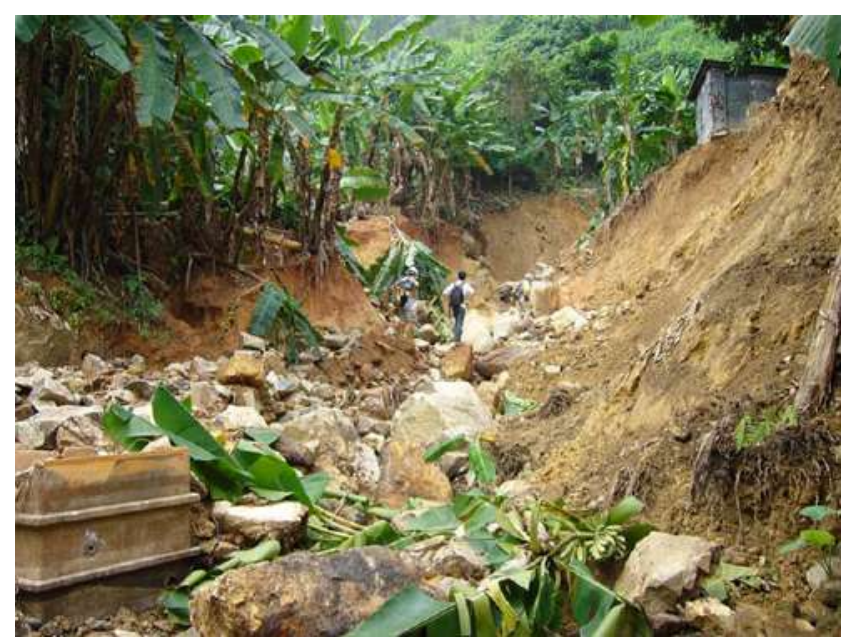

Fig. 10. Erosion of slopes nos. 7SW-A/F76 and 7SW-A/F77 caused by debris flood at approximate chainage $\mathrm{CH} 66$ (Maunsell Geotechnical Services Limited (MGS, 2006), photograph taken on 25 August 2005)

The debris flow arrived at an access road, intercepting it approximately $226 \mathrm{~m}$ below the weirs, blocking the crossroad drain and overtopping the road, there splitting into two branches which later joined the main stream. The run out was approximately $800 \mathrm{~m}$ from the weirs to Lo Wai Road, where

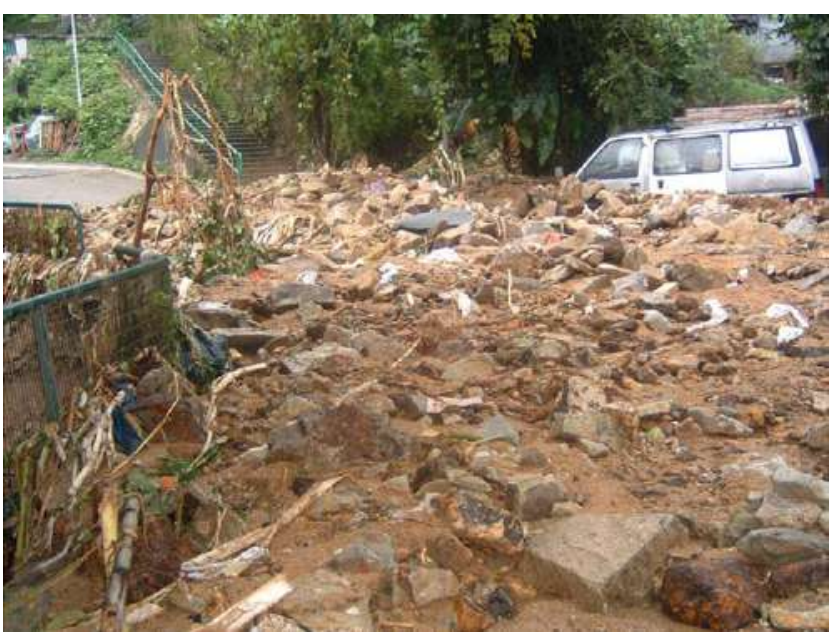

Fig. 11. Debris deposited on access road leading to Lo Wai road (photograph taken on 21 August 2005)

it finally stopped, depositing large amounts of debris (Figs 11 and 12).

Modelling: the depth-integrated SPH model. The model used in the present analysis is a Lagrangian depth-integrated model, which is discretised using the SPH technique. 


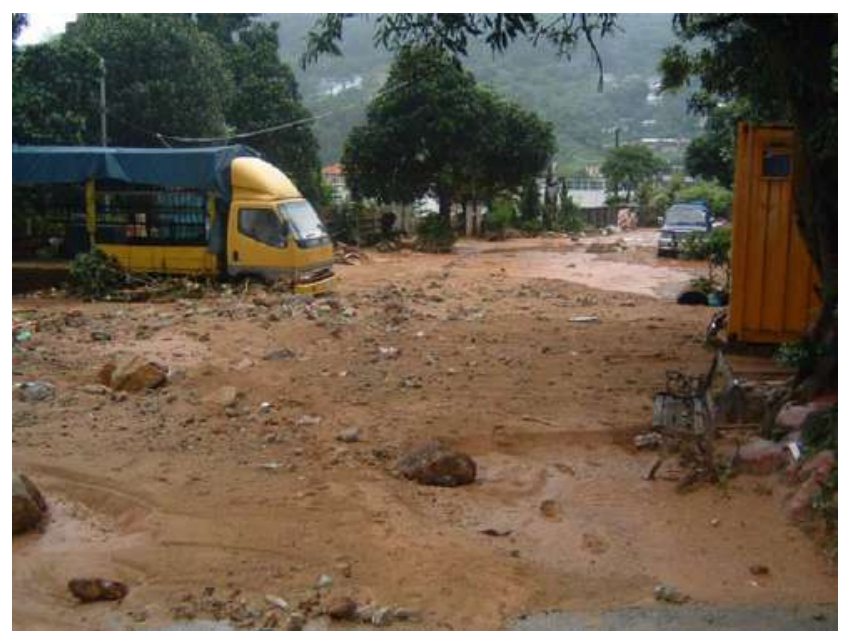

Fig. 12. Debris deposited on access road leading to Lo Wai road (Maunsell Geotechnical Services Limited (MGS, 2006), photograph taken on 21 August 2005)

The method was proposed by Pastor et al. (2009a, 2009b). One important advantage of the Lagrangian formulation is that particles carry with them information regarding solid concentration and rheological properties of the fluid, which are changing with erosion. Therefore, no convection of these properties was done, with an increase of accuracy and simplicity because fewer equations were used.

The model is obtained from a set of equations describing the coupled behaviour of saturated geomaterials, where soil particles and pore fluid can move relatively to each other (Zienkiewicz et al., 1999; Pitman \& Le, 2005; Pastor et al., 2017). From here, simpler formulations are obtained, such as those based on velocities and pore pressures (Zienkiewicz et al., 1999).

In order to solve the above-mentioned system of equations, three-dimensional (3D) models require a very high computational effort. As an alternative, depth-integrated models have been used to study landslide propagation since 1989, when Savage \& Hutter (1991) proposed their much celebrated one-dimensional (1D) Lagrangian model. Further research by Hutter \& Koch (1991) and others extended this model to more general conditions. It has been applied by Laigle \& Coussot (1997), McDougall \& Hungr (2004) and Pastor et al. (2009a, 2009b); the text book by Pudasaini \& Hutter (2007) is also worth mentioning here. Therefore, a depth-integrated approach is considered, in the present work, to provide a reasonable compromise between computational cost and accuracy.

The mathematical model is formulated in two dimensions, using the depth of the moving mass and the depth-averaged velocities as main variables. The model includes laws describing bottom friction and basal erosion, which are two important problems in the case studied in the present paper. The interested reader will find an interesting account of the limitations of Savage-Hutter and depth-integrated models in the paper by Hutter et al. (2005).

The numerical model chosen here is the SPH model. SPH is a meshless method where information of field variables is carried by moving nodes or particles. Functions and differential operators such as gradient and divergence at a given node are obtained from neighbouring nodes.

It is important to note that the model proposed here does not include pore water coupling, as the flowing material is of cohesive-viscous type and has been modelled using a
Bingham model, with parameters depending on the soil concentration in the mixture.

The SPH method was introduced by Lucy (1977) and Gingold \& Monaghan (1977) for astronomical modelling. Since then, it has been applied to model problems in hydrodynamics (Monaghan et al., 1999), flow through porous media (Zhu \& Fox, 2001), shallow water flows (Ata \& Soulaïmani, 2005; Xia et al., 2013; Vacondio et al., 2013a, 2013b, 2013c) and avalanche propagation (McDougall \& Hungr, 2004; Rodriguez-Paz \& Bonet, 2005; Pastor et al., 2009a, 2009b), just to mention a few representative cases.

Balmforth \& Liu (2004) or Liu \& Liu (2003) provide good reviews of 3D modelling of geotechnical problems.

Details of both the mathematical and the numerical model are given in the Appendix.

Practical modelling details. From the modelling point of view, the Lo Wai case presents the following main difficulties.

(a) The topographical information provided in the digital terrain model (DTM) does not have enough accuracy to model singular elements such as small bridges, drains and so on.

(b) The existence of walls in some parts of the path requires the introduction of zero normal velocity conditions, as the flow is confined by them.

(c) Definition of the input, which is the water flowing through both weirs. The main problem here is to inject water particles into the computational domain, boundary conditions depending on Froude number or on the knowledge of flow properties through the weirs.

(d) The material properties of the flow depend on the amount of entrained solids, and an evolution law has to be proposed. Erosion and suitable rheological laws will be provided in next section.

\section{Terrain representation}

One important issue is the representation of the terrain over which the avalanche moves, as it greatly influences the results. If the height of the terrain at node $\mathrm{I}$ is denoted by $Z_{\mathrm{I}}$, it is necessary to obtain: $(a)$ its gradient, $\operatorname{grad} Z_{\mathrm{I}}$, and $(b)$ the radius of curvature along the tangent to the node path, which can be obtained from the second-order derivatives of $Z$ (in case the flowing material is frictional).

In the case of fast landslides, the terrain information is given on a DTM, which consists of a series of values $\left(x_{k}, y_{k}, z_{k}\right)$ at the nodes of a structured grid. From here, both gradients and second derivatives at the grid nodes can be obtained using a classical nodal recovery technique on a finite-element mesh, the nodes of which are those of the DTM grid.

The DTM consists of a set of $40658(x, y, z)$ points provided by Hong Kong Geotechnical Office. The spacing of the points is $5 \mathrm{~m}$. The points are arranged in a structured rectangular grid. This allows the generation of a temporary finite-element mesh of four-noded quadrilaterals or threenoded triangles. From here, the topography module of the SPH code obtains at all nodes the $x$ and $y$ slopes, together with the second-order derivatives in case the material is frictional, as centrifugal contributions to acceleration will be needed. The technique that the present authors use to obtain derivatives at nodes is the same as that used in finite-element codes to obtain stresses at nodes from stresses at elements: variational recovery. From the values of terrain elevation at 
nodes $Z$, derivatives inside the DTM elements are obtained, which are projected back onto the nodes.

\section{Wall boundary conditions}

Boundary conditions require special treatment. SPH practitioners use special virtual particles located at the boundaries. Monaghan (1982) introduced a first type of virtual particles, often referred to as 'type 1 virtual particles', which applies a repulsive force on particles approaching the boundary, preventing boundary penetration by them.

Libersky et al. (1993), and Randles \& Libersky (1996) introduced a second type of virtual particles, which are located symmetrically with respect to a real particle approaching the boundary.

The condition that will be imposed consists in making only the normal velocity zero, leaving free the tangential velocity to the wall, which is equivalent to a free slip condition.

In the present case, the wall boundary conditions are introduced using a set of wall nodes that define the wall. Once an interaction between a wall node and a fluid node is detected, the normal velocity to the wall is made zero. This is important in cases such as Lo Wai, where side walls exist (see Fig. 13). The wall elements are defined as lines along which sets of zero normal velocity nodes are defined. In Lo Wai, the authors have used three sets of such elements. The code labels them as zero normal velocity nodes $\left(v_{\mathrm{n} 0}\right)$, and when an interaction between a SPH node and one $v_{\text {n0 }}$ node occurs, normal velocity to the wall is made zero.

\section{Boundary conditions: injection of nodes into the domain - hydrograms}

In the case of shallow water waves, the boundary conditions of absorbing and prescribed incoming waves are important, and have been applied to depth-integrated problems using finite elements by Peraire et al. (1986) or SPH by Lastiwka et al. (2005) and Vacondio et al. (2011).

In the Lo Wai case, water particles enter the domain from the two overflow weirs once the catchwater channel has been blocked by the two landslides described above (see Fig. 5). The boundary conditions to be imposed depend on the Froude number, defined as

$$
F=\frac{|\bar{v}|}{\sqrt{\mathbf{g h}}}
$$

In the case where Froude number is higher than 1, supercritical conditions exist, and it is necessary to prescribe both the height and the averaged velocity of the incoming particles.

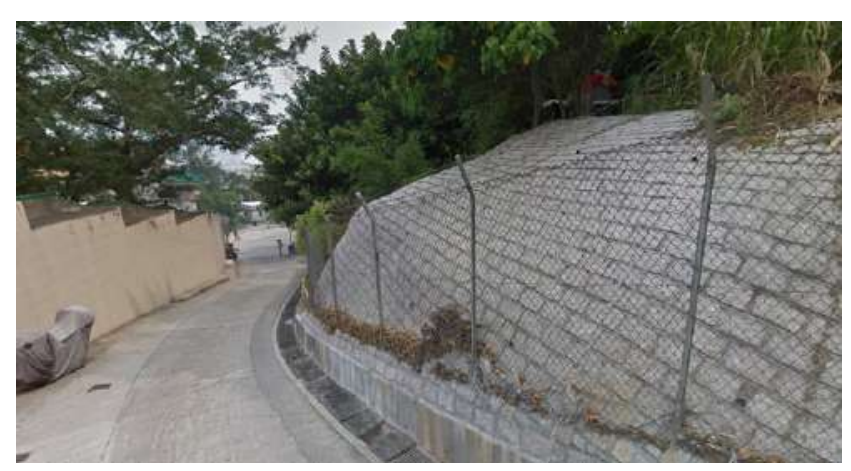

Fig. 13. General view of the debris flood trail, downstream of the cross road
In the case where the flow at the gate is subcritical, only one variable - velocity or height - is prescribed, the remaining variable being obtained by using the Riemann invariants

$$
\begin{aligned}
& R^{(1)}=2 \sqrt{\boldsymbol{g} h}+\bar{v} \\
& R^{(2)}=2 \sqrt{\boldsymbol{g} h}-\bar{v}
\end{aligned}
$$

which characterise the waves coming into the domain or leaving it, respectively.

At time $n+1$, the values of heights and velocities in the domain will be obtained, without applying this boundary condition. They will be called $h^{*}$ and $\bar{v}^{*}$.

From here, the outgoing Riemann invariant $R^{(2)^{*}}$ is obtained as

$$
R^{(2)^{*}}=2 \sqrt{\mathbf{g} h^{*}}-\bar{v}^{*}
$$

If the hydrograph $\bar{h}(t)$ is known, assuming that the outgoing Riemann invariant will not change, it follows that

$$
R^{(2) n+1}=2 \sqrt{\boldsymbol{g} \bar{h}^{n+1}}-\bar{v}^{n+1}=R^{(2)^{*}}=2 \sqrt{\boldsymbol{g} h^{*}}-\bar{v}^{*}
$$

From where we will obtain the depth averaged velocity at time $(n+1)$ as

$$
\overline{\boldsymbol{v}}^{n+1}=2 \sqrt{\boldsymbol{g} \bar{h}^{n+1}}-2 \sqrt{\boldsymbol{g} h^{*}}+\bar{v}^{*}
$$

In the case where it is desired to prescribe the velocity, the flow depth will be obtained by

$$
2 \sqrt{\boldsymbol{g} \bar{h}^{n+1}}=\bar{v}^{n+1}-\bar{v}^{*}+2 \sqrt{\boldsymbol{g} h^{*}}
$$

In conclusion, Riemann invariants characterise magnitudes exiting and entering the domain. If the normal to the domain is considered, the second invariant corresponds to the outgoing wave. This is the reason why the boundary condition is imposed on the second invariant only. The time step algorithm is implicit, and heights and velocities at time $(n+1)$ are computed at the boundary without imposing any boundary condition. From these values, the information of the outgoing wave is obtained - namely, the second invariant. Knowing that, together with the normal velocity at time $(n+1)$, it is possible to obtain the velocity.

Alternatively, if flow properties at the gate are known, it is possible to prescribe both height and velocity at all injected particles. This method is implemented in the model by defining (a) gates, through which particles are injected, and (b) pools, which are fictitious reservoirs of particles used in the analysis to apply the boundary condition at the gate. Indeed, the values of $h^{*}$ and $\bar{v}^{*}$ are assigned to these pool particles.

Particles are injected into the domain when the distance between the gate and the last series of injected particles is equal to or larger than the average particle spacing (Fig. 14).

In Lo Wai, the authors have implemented two gates and pools as there are two overflow weirs. Until the end of the calculation 2814 of particles were injected to the domain. In the case under consideration, the authors have found that injecting lines of three particles at a time provided sufficient accuracy.

To impose the velocity and height of fluid at the gate, a pool of SPH nodes is used, with values of height and velocity obtained using the boundary conditions described above. Here, the authors have chosen to determine these values by using a suitable side weir formula provided by Cheong (1991), where

$$
q=\bar{C}_{\mathrm{d}} \sqrt{2 \boldsymbol{g} h_{\mathrm{w}}}
$$




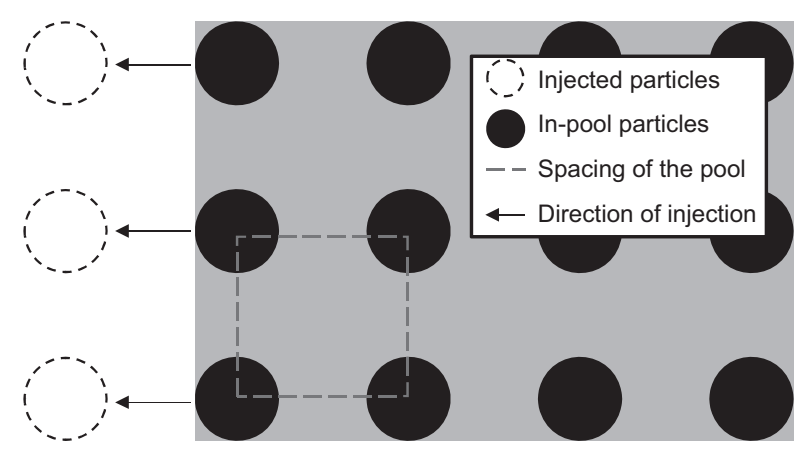

Fig. 14. The injection method

with $\bar{C}_{\mathrm{d}}=0.45-0.22 F^{2}, F$ being the Froude number in the channel.

Taking into account the weir geometry - the water flows into a horizontal slab located $2 \cdot 2 \mathrm{~m}$ below the surface of the water -the outflow velocity into the model has been estimated as $1 \mathrm{~m} / \mathrm{s}$, with $h_{\mathrm{w}}=0.66 \mathrm{~m}$.

\section{Neighbour search}

Finally, here is a short comment regarding neighbour search. The authors used an auxiliary structured grid covering the part of the terrain where the SPH particles are located. Spacing of the auxiliary grid is related to the smoothing length. For a given SPH node, the search is restricted to the cell where it belongs and its neighbours. This temporary grid is valid only for a given time step. In cases where the flow is elongated, the grid can be oriented automatically following the main inertia axes of the set of $\mathrm{SPH}$ nodes on the domain.

\section{A note on accuracy}

As in any numerical method, accuracy is an important issue. In the case of finite elements, the size of elements relative to a representative length is a key factor. For instance, when dealing with dynamic problems, more than 12 elements per wave length are required. Here, the problem is not the number of particles per unit length, but the number of particles belonging to the influence region of each one. This is controlled by the smoothing length, which is updated at every time step in order to maintain a suitable number of interacting particles. Moreover, it should be noted that it depends on the particles' distribution. Linear or quasi-linear distributions will have a smaller number of interactions than circular ones. In the present case, the average number of interactions is close to 30 , which is considered reasonable.

\section{RHEOLOGICAL BEHAVIOUR \\ Geological setting}

Lo Wai is located in Sha Tin district, $2 \mathrm{~km}$ south of Tai Mo Shan massif (957 m) (Fig. 1). According to the Hong Kong Geological Survey memoir 1 of June 1986, underlying rocks are mesozoic sedimentary and volcanic rocks, with superficial deposits consisting of Holocene and Pleistocene alluvium, debris flow deposits, rockfall deposits, mixed debris flows and talus deposits, and slide deposits. Rocks in the upper $10 \mathrm{~m}$ have been subjected to chemical-induced weathering.

The Lo Wai area deposits are debris flow deposits, presenting poor sorting, and materials with sizes ranging from blocks and boulders to much finer materials, such as gravel and clay. According to the memoir, 'the deposits comprise boulders and cobbles supported by a gravelly clay matrix ... the debris flow deposits derived from a number of sources lateral to the river and therefore variable.'

\section{Rheological model}

From a rheological point of view, pure water behaves as a Newtonian fluid, with a basal shear stress which can be modelled using simple formulae, such as Manning's. However, in the Lo Wai case, the material flowing from the catchwater channel weirs down to Lo Wai road evolved from pure water to a mixture of water and solids entrained by erosion in the upper part of the natural stream courses, where side slopes failed, with the material falling into the courses.

If the entrained material contains fines, the mixture behaves as a cohesive-viscous fluid, with a yield stress that will depend on the solid fraction. At early stages, these flows are classified as hyper-concentrated flows or debris floods. As more material is entrained, the yield stress increases up to a point at which it can suspend larger particles, such as gravel or boulders, becoming a debris flow.

Based on the geological setting described above, the present authors assume (see paragraph on geological settings and Fig. 5) that the entrained material consists of boulders and cobbles supported by a gravelly clay matrix, the finer fractions being incorporated first to the flow. Therefore, the fluid will be considered as a non-Newtonian fluid of Bingham type, with yield stress and viscosity dependent on solid particles concentration.

To obtain the basal shear stress, the flow is assumed to be steady, simple shear flow (infinite landslide), where the depth is constant and the velocities depend only on the depth. Under these conditions, the balance of momentum equation can be integrated, providing the velocity profile and the shear stress distribution along the depth, from which a relation between the depth-averaged velocity and the basal shear stress is obtained. In the case of Bingham fluids, the expression relating the averaged velocity to the basal friction for the infinite landslide problem is

$$
\bar{v}=\frac{\tau_{\mathrm{B}} h}{6 \mu}\left(1-\frac{\tau_{\mathrm{Y}}}{\tau_{\mathrm{B}}}\right)^{2}\left(2+\frac{\tau_{\mathrm{Y}}}{\tau_{\mathrm{B}}}\right)
$$

where $\mu$ is the viscosity; $\tau_{\mathrm{Y}}$ is the yield stress; and $\tau_{\mathrm{B}}$ is the shear stress on the bottom.

In the above expression, the basal shear stress cannot be obtained analytically, and it is necessary to obtain the roots of a third-order polynomial.

The approach proposed by Pastor et al. (2004) is now extended, consisting of using the best second-order approximation. The above expression can be transformed into

$$
P_{3}(\xi):=\xi^{3}-(3+a) \xi+2=0
$$

where $\xi=h_{\mathrm{P}} / h$ has been introduced, which is the ratio between the height of the constant velocity region or plug to the total height of the flow, and the non-dimensional number $a$ defined as

$$
a=\frac{6 \mu \bar{v}}{h \tau_{\mathrm{Y}}}
$$

The best approximation in the uniform distance sense of the third-order polynomial is given by

$$
P_{2}(\xi)=\frac{3}{2} \xi^{2}-\left(\frac{57}{16}+a\right) \xi+\frac{65}{32}
$$


Knowing the non-dimensional number, $a$, the root $\xi$ is obtained immediately; the basal shear stress follows at once as

$$
\tau_{\mathrm{B}}=\frac{\tau_{\mathrm{y}}}{\xi}
$$

This approximation is valid for many practical cases. However, for very low or very high values of the nondimensional number $a$, the law can be improved as

$$
\tau_{\mathrm{B}}=\left\{\begin{array}{cc}
\frac{3 \mu \bar{v}}{h} & a>50 \\
\frac{\tau_{\mathrm{y}}}{\xi} & 50 \geq a \geq 0.01 \\
\tau_{\mathrm{y}} & 0.01>a
\end{array}\right.
$$

Figure 15 presents a comparison of the exact and approximate values of the relative plug height $\xi$ for different values of the parameter $a$ in three different characteristic intervals.

To account for dependence on concentration of solid particles, the present authors have used a Bingham law with an evolution law with $\tau_{\mathrm{y}}=\tau_{\mathrm{y} 0} f(s)$ and $\mu=\mu_{0} f(s)$, where $s$ is the volume concentration of solid particles. The reference value $s_{0}$ is now introduced, at which the change from debris flood to debris flow takes place. This value lies in the range $0 \cdot 6-0 \cdot 7$. The values of the yield stress and the viscosity will be defined at this reference volume concentration, and they will be denoted as $\tau_{\mathrm{y} 0}$ and $\mu_{0}$.

The laws proposed by O'Brien \& Julien (1988), which have been used by Komatina \& Jovanovic (1997), Chen et al. (2018) and Li et al. (2017), can be cast using the above reference values as

$$
\left(\tau_{\mathrm{y}} / \tau_{\mathrm{y} 0}\right)=\left(s / s_{0}\right)^{\beta 1}\left(\mu / \mu_{0}\right)=\left(s / s_{0}\right)^{\beta 2}
$$

where $\beta_{1}, \beta_{2}$ are two rheological parameters to be determined in the laboratory.

In this paper, the alternative law is proposed

$$
f(s)=1-\exp (-\beta s)
$$

and

$$
\left(\tau_{\mathrm{y}} / \tau_{\mathrm{y} 0}\right)=\frac{1-\exp (-\beta s)}{1-\exp \left(-\beta s_{0}\right)}\left(\mu / \mu_{0}\right)=\frac{1-\exp (-\beta s)}{1-\exp \left(-\beta s_{0}\right)}
$$

This law has been complemented to take into account the behaviour of pure water when running down a vegetated slope, and the friction has been chosen as the maximum of the evolution law and that provided by the Manning formula.

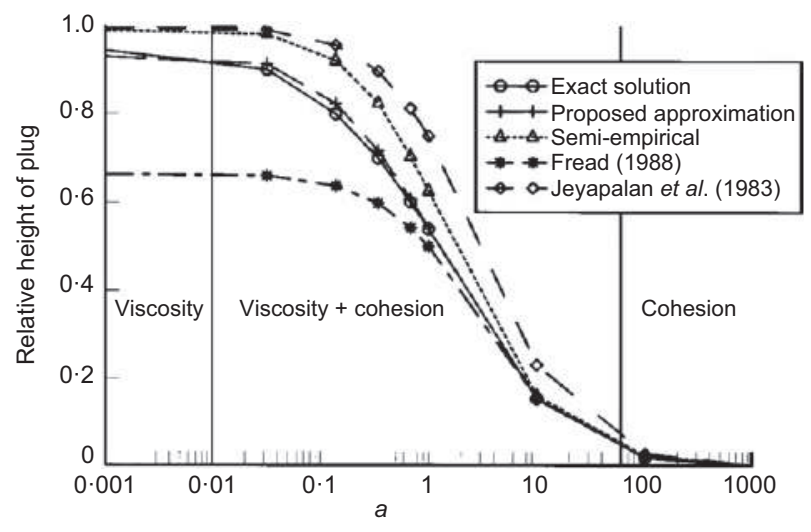

Fig. 15. Comparison of the proposed approach and other simplified formulas (Pastor et al., 2004)
In the SPH model, the evolution of solid concentration caused by erosion is accounted for by storing the volume associated with every particle. The initial volume is denoted $m_{0}$ and, in the Lo Wai case, it corresponds to a zero volume concentration of solids. As material is entrained through erosion, this associated volume changes, depending on time. At a given time $t$, the associated volume - made of soil and water - is denoted $m(t)$.

The solid concentration is therefore obtained as

$$
s=\frac{m(t)-m_{0}}{m(t)}
$$

Once $s$ is known, the rheological properties of the soilwater mixture are obtained immediately.

The implementation in the SPH code is straightforward when concentration is very small: the basal frictions provided by the Bingham model and by a simple Manning law are compared, and the highest value is chosen.

The evolution formula proposed herein is based on selecting a reference concentration $s_{0}$ which characterises the transition from debris flood to debris flow. The authors have selected a value of $s_{0}=0 \cdot 6$.

The reference values of the yield stress and the dynamic viscosity have been estimated by back-analysis as $\tau_{\mathrm{y} 0}=33.8 \mathrm{~Pa}$ and $\mu=0.025 \mathrm{~Pa} \mathrm{~s}$, with an evolution parameter $\beta=0 \cdot 5$.

The evolution law is provided in Fig. 16. Table 1 summarises the parameters used in the study.

Therefore, to characterise the material behaviour, four parameters have been used: the yield stress, the viscosity, the evolution parameter and the erosion coefficient. Calibration consists of obtaining a set of reasonable and consistent values which minimise the difference between the observations and the predictions. There exist automatic optimisation methods, such as those used by Calvello \& Finno (2004) or Brezzi et al. (2016). In the present case, the authors have chosen a trial-and-error procedure. The main problem has been the

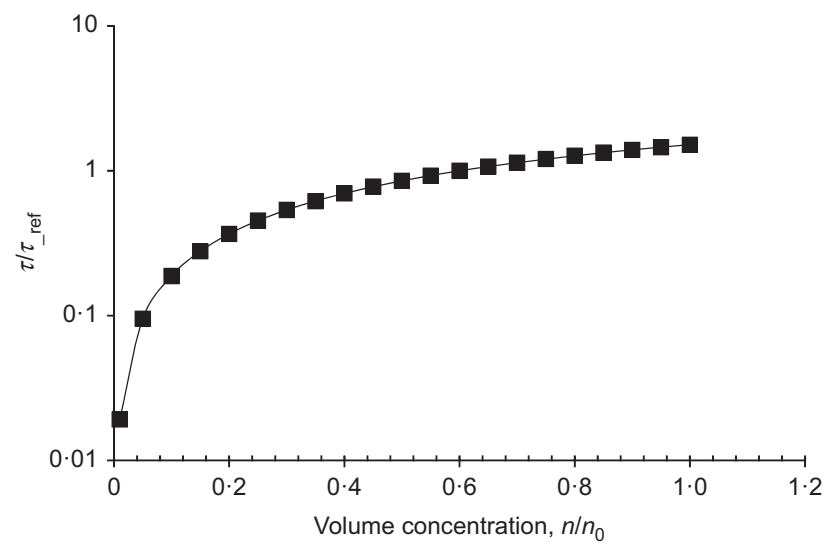

Fig. 16. Proposed non-dimensional evolution law

Table 1. Parameters to model Lo Wai debris flood

Lo Wai debris flow

\begin{tabular}{l|l} 
Density (water) & $1000 \mathrm{kN} / \mathrm{m}^{3}$ \\
Rheological model & Bingham \\
Cohesion & $33.8 \mathrm{~Pa}$ \\
Viscosity & $0.025 \mathrm{~Pa} \mathrm{~s}$ \\
Evolution parameter & 0.5
\end{tabular}


lack of rheometer tests for mixtures of soil with different contents of water.

\section{A note on erosion}

One important aspect in the behaviour of debris floods and related phenomena is erosion. This complex phenomenon requires a rheological or constitutive behaviour of the interface, and depends on variables such as the flow structure, density and size of particles, as well as on how close the effective stresses at the surface of the terrain are to failure.

In some cases, the basal entrainment can increase the mass of debris flows. As an example, in the debris flow of Tsing Shan (Hong Kong, 2000) an initial volume of $150 \mathrm{~m}^{3}$ increased up to $1620 \mathrm{~m}^{3}$. The authors reproduced the observed erosion using a depth-integrated SPH model (Pastor et al., 2007, 2009a, 2009b) and Hungr's law.

This law, proposed by Hungr \& Evans (2004) and Hungr et al. (2005) gives the erosion rate as $e_{\mathrm{R}}=E_{\mathrm{s}} h \bar{v}$ where $E_{\mathrm{s}}$ can be obtained directly from the initial and final volumes of the material and the distance travelled as $E_{\mathrm{s}} \approx\left[\ln \left(V_{\text {final }} / V_{0}\right) /\right.$ distance $]$. Units of erosion coefficient are $\mathrm{L}^{-1}$. In the case considered here, the authors have selected a value of Hungr's coefficient of $E_{\mathrm{s}}=0.005 \mathrm{~m}^{-1}$.

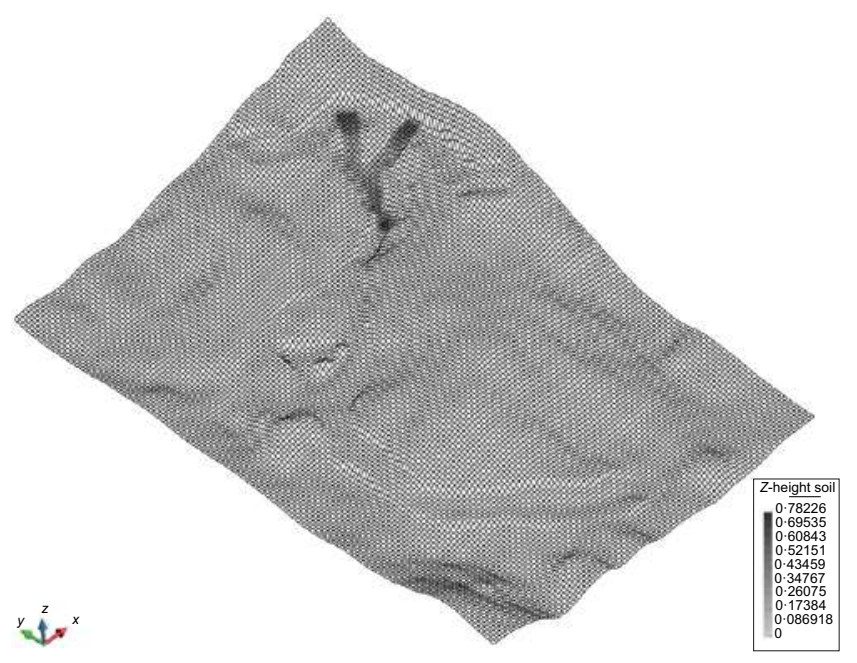

$t=20 \mathrm{~s}$

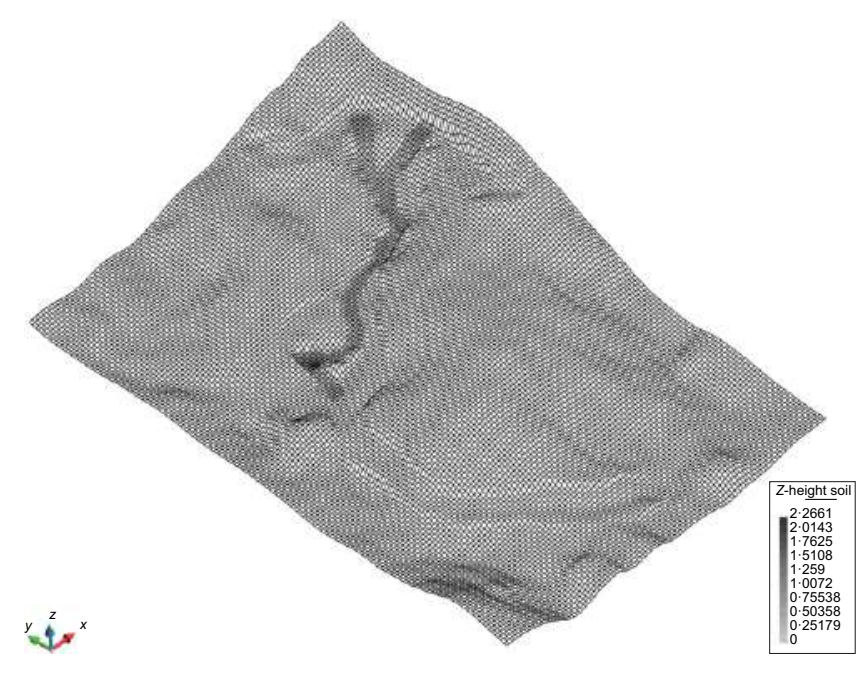

$t=60 \mathrm{~s}$
Model predictions and validation

The purpose of this section is twofold: $(a)$ to compare model predictions with the observed results, and $(b)$ to provide information on some features of the debris flood which were not measured or reported.

Debris flows and floods are rapid phenomena, which are difficult to forecast in space and time. Therefore, it is not usual to deploy sensors at all possible locations where such events occur. For the case of Lo Wai analysed in the present paper, the authors have used the valuable - but limited information provided by the Hong Kong Geotechnical Office, as reported by Maunsell Geotechnical Services Limited (MGS, 2006), which consists of

(a) the path followed by the debris flood

(b) the thickness of the deposits left on the path

(c) the basal erosion observed in parts of the stream courses.

All of them were obtained once the flow had stopped.

Therefore, model validation is based on comparing the propagation path, thickness of the deposits and basal erosion (location and maximum values). These observations and predictions can be used to predict future events,

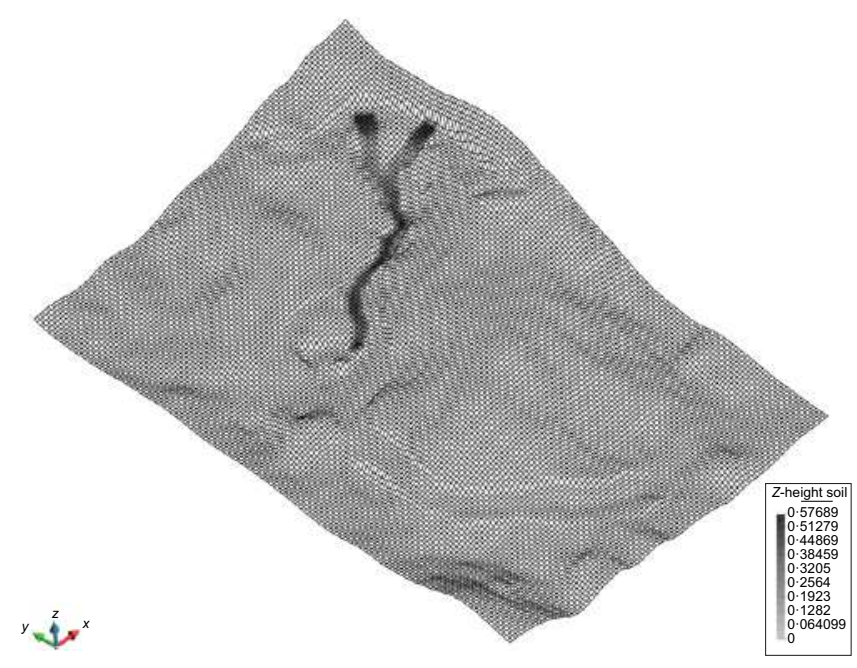

$t=40 \mathrm{~s}$

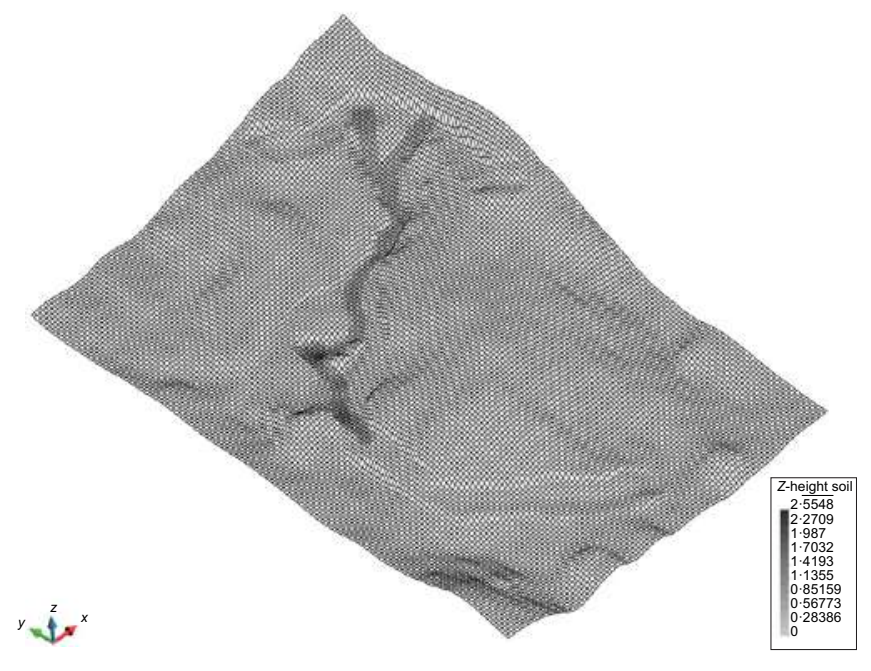

$t=80 \mathrm{~s}$

Fig. 17. Time-lapse images of the simulation (shades refer to the height of the debris flows) (continued on next page) 


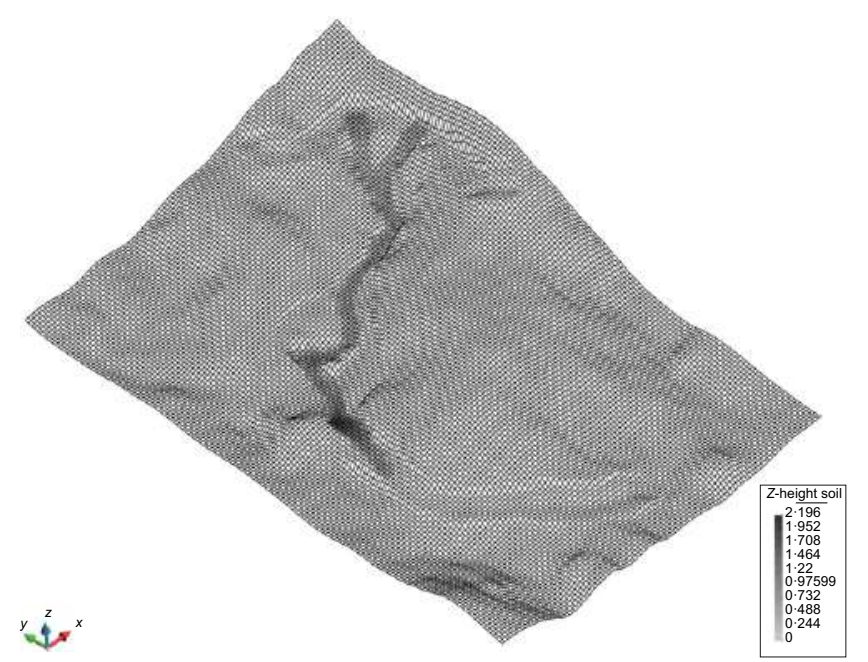

$t=100 \mathrm{~s}$

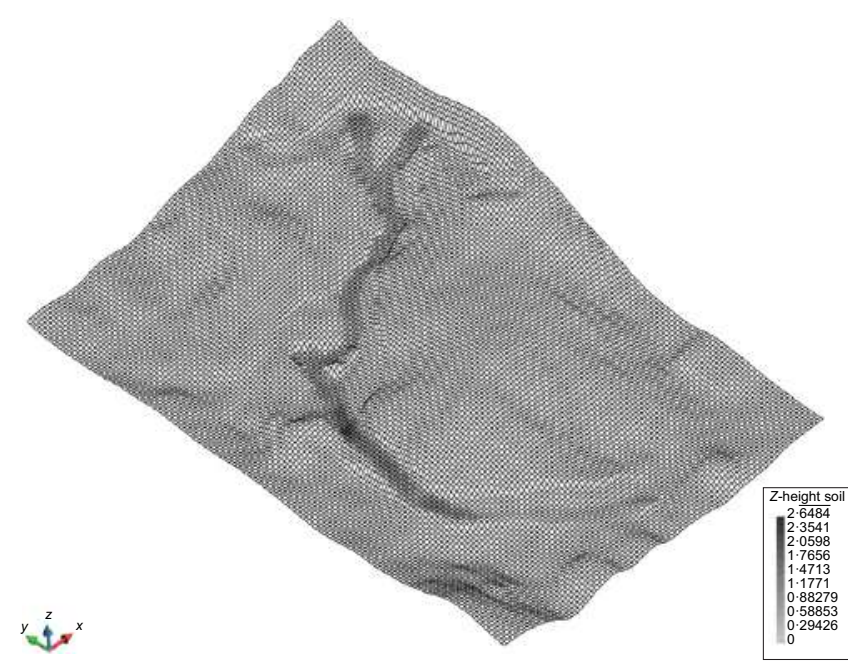

$t=140 \mathrm{~s}$

Fig. 17. Continued

where engineers will have to know paths, deposits' extensions and thicknesses, entrainment materials, density of the flow along the path and velocities, in order to design suitable mitigation measures. Impact forces, for instance, depend on the thickness, density and the velocity of the flow.

First of all, in the eight image panels provided in Fig. 17 the evolution of the flow at times 20, 40, 60, 80, 100, 120, 140 and $160 \mathrm{~s}$ is shown, respectively. The scales in each image provide the thickness of the deposits, and agree reasonably well with the values given in the report (MGS, 2006). The debris flow followed the main channels, and flooded a parking space close to the path, as depicted in Fig. 18. The parking was flooded $60 \mathrm{~s}$ after initiation, approximately (see subpanel $60 \mathrm{~s}$ in Fig. 17).

Regarding depth of flow, it can be seen in Fig. 17 that, in the upper branches, it is less than $1 \mathrm{~m}$, whereas after arriving at the parking zone it increases, there reaching $2 \mathrm{~m}$, with a decrease of velocity. The situation at $t=160 \mathrm{~s}$ shows how maximum depths have decreased.

Figure 18 provides a comparison between the observed (Fig. 18(a)) and the predicted (Fig. 18(b)) paths. They coincide well, except in the middle part, where the flow bifurcated into a sub-branch. This was caused by the

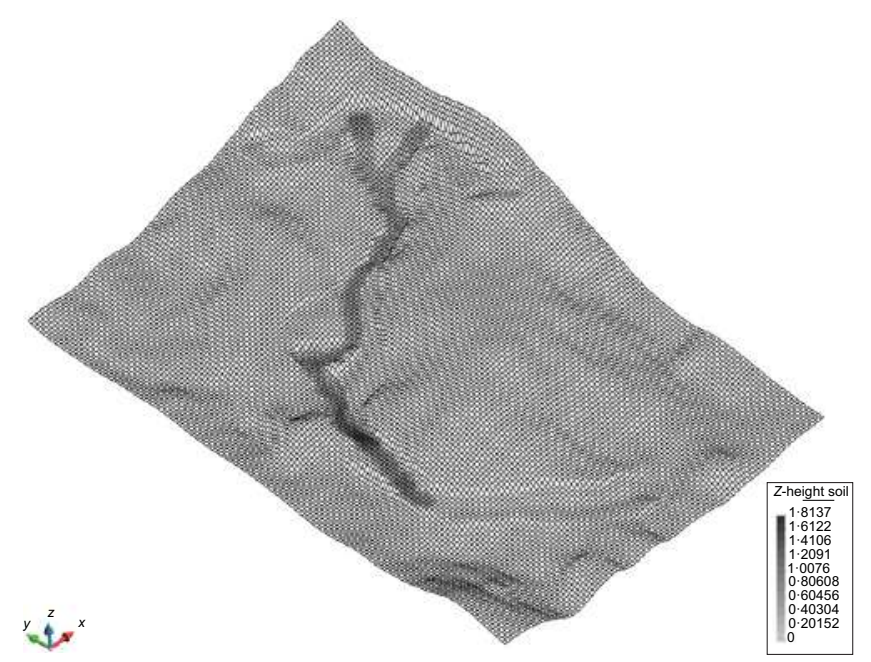

$t=120 \mathrm{~s}$

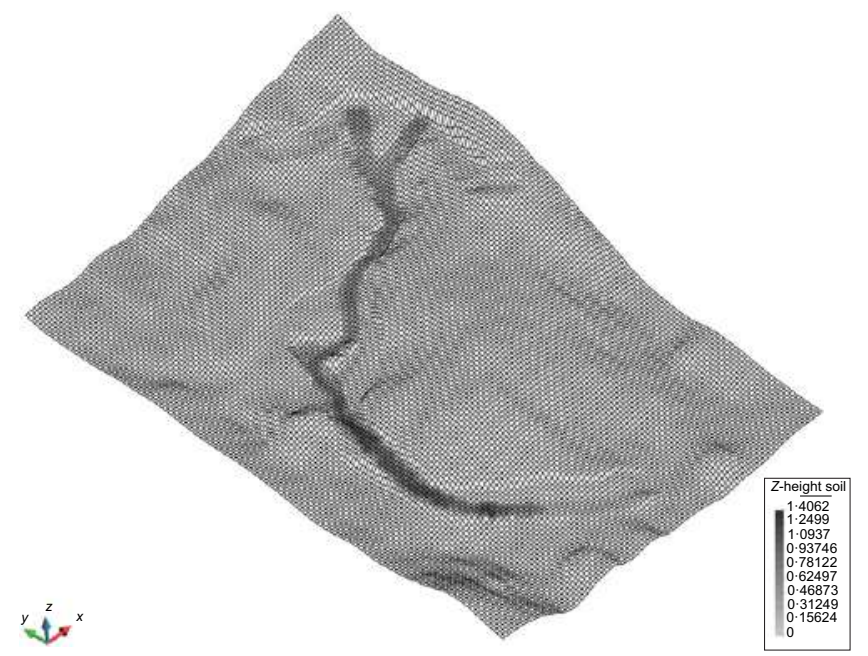

$t=160 \mathrm{~s}$

existence of a channel between slopes 7SW-AF/38 and 7SW-AF/76. As the digital terrain model was not giving enough accuracy here, the authors decided not to introduce it artificially (see Fig. 22 later, where the DTM grid is depicted).

The thickness of the deposits on the car park, indicated by the label 'Vehicles' in Fig. 18, is in agreement with the values given in the report. It took some $3 \mathrm{~min}$ for the flow to arrive at Lo Wai. Taking into account that the distance is approximately $340 \mathrm{~m}$, this gives an average propagation speed of $7 \mathrm{~km} / \mathrm{h}$.

One important aspect of the analysis is the erosion which took place in the natural channels, as the entrainment results on increasing mixture density and rheological properties. The amount of entrained material depends mainly on its availability (maximum erodible depth) and the velocity of the flow. In order to assess how the proposed model is able to reproduce where erosion was more important and the eroded depth, Fig. 19 provides both the observed results (Fig. 19(a)) and the model predictions (Fig. 19(b)) at a point labelled as $\mathrm{CH}$ 72. The location of this section $\mathrm{Y}-\mathrm{Y}$ is given in Fig. 20. According to the Maunsell report, the approximated erosion at $\mathrm{Y}-\mathrm{Y}$ section is $3 \mathrm{~m}$, which agrees well with the model predictions (close to $3 \mathrm{~m}$ ). 


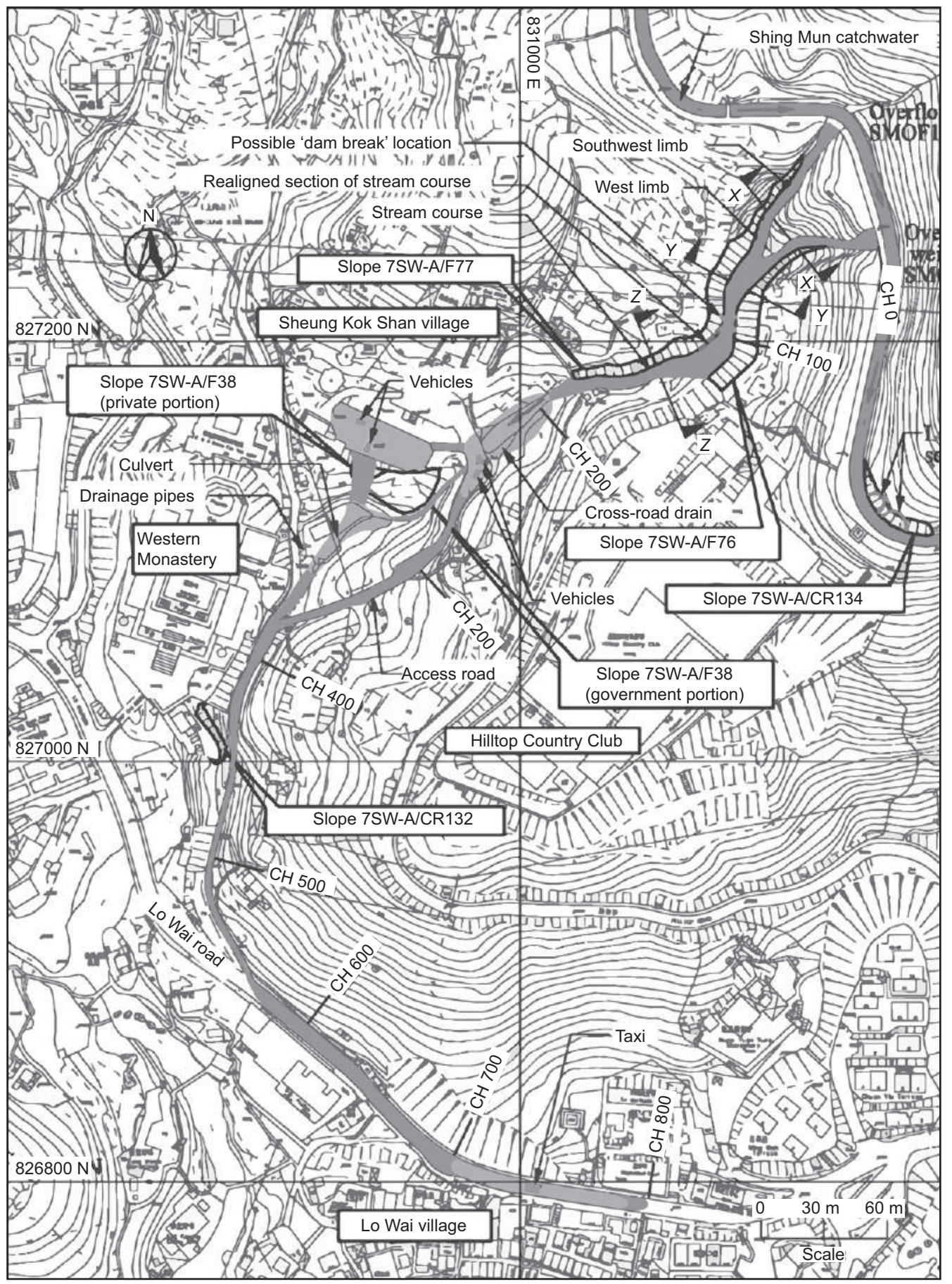

Fig. 18. Lo Wai debris flow. Computation with channelling barriers: (a) observation compared against (b) computed results (continued on next page)

Regarding the zones where erosion was more important, the isolines of total erosion are provided in Fig. 20. It can be seen how this was produced only in the upper part of the stream, where velocities were higher, because of the lower basal friction and the higher slope.

So far, the model results have been compared to the observations described in the report by Maunsell Geotechnical Services Limited (MGS, 2006). The model can be used to provide information on local velocities and heights, which are important to assess the effect of the flow on structures.

Regarding the velocities, in the eight image panels provided in Fig. 21 the depth-averaged velocity at times $20,40,60,80,100,120,140$ and $160 \mathrm{~s}$ are depicted, respectively. They are relatively high, reaching up to $14 \mathrm{~m} / \mathrm{s}$ approximately.

In addition to depending on velocity, the type of flow depends on Froude's number as well, which is given by $F=u / \sqrt{\mathbf{g} h}$. When $F$ is larger than unity, the flow is referred to as supercritical, otherwise it is subcritical.

The authors have selected a node in the digital terrain model, labelled 10900 , in order to study the evolution of the Froude number, height and averaged velocity as a function of time. This point is located at the middle of the path, approximately. Its position is given in Fig. 22.

The evolution of the depth of the flow and its depth-averaged velocities are given in Fig. 23. It is interesting to note that the flow is supercritical, as the Froude number 


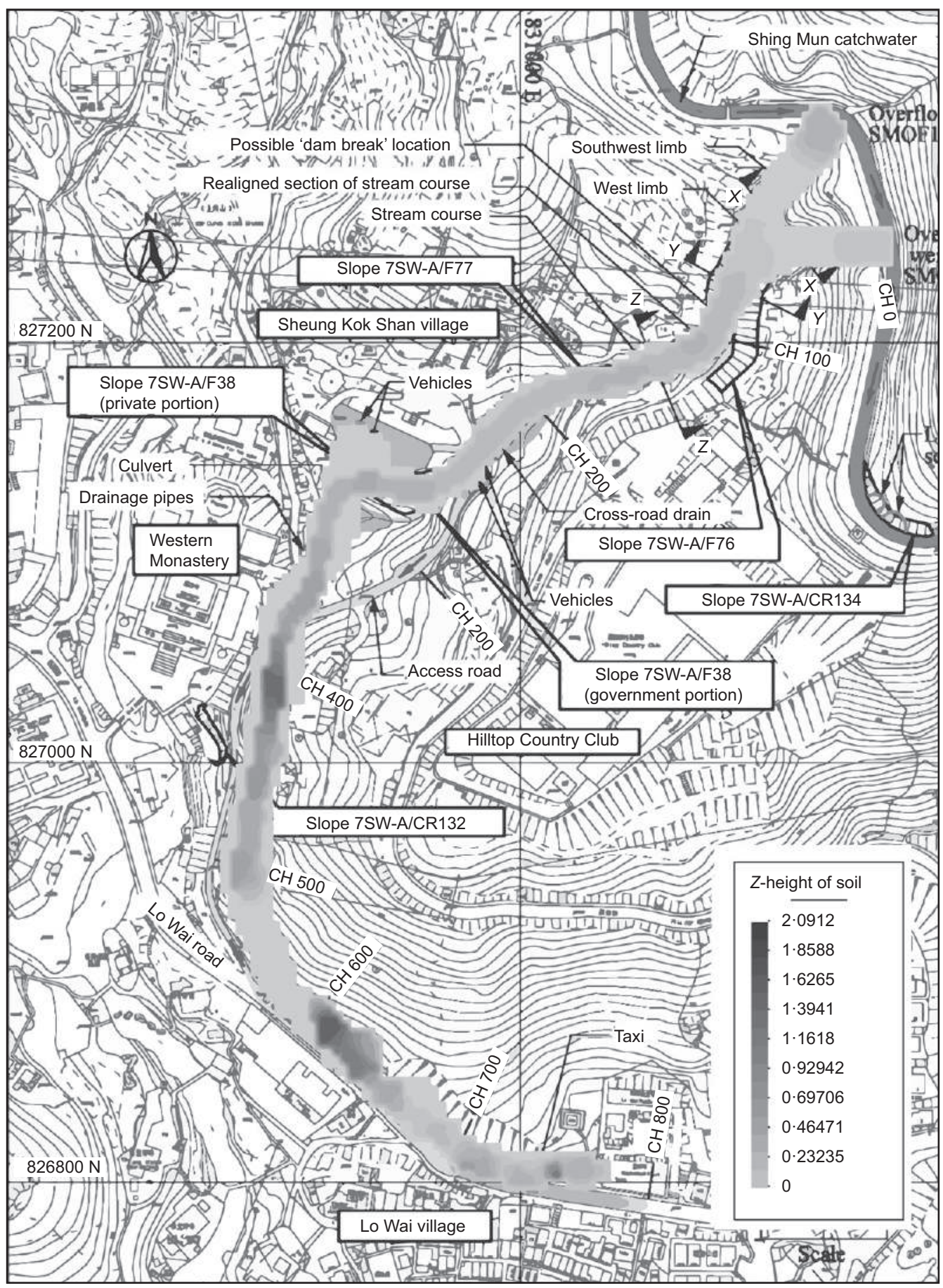

Fig. 18. Continued

from time $140 \mathrm{~s}$ is $F=u / \sqrt{\mathbf{g} h}=7 / \sqrt{0 \cdot 5 \boldsymbol{g}}>1$. Indeed, it can be seen to be supercritical up to $160 \mathrm{~s}$.

\section{CONCLUSIONS}

This paper has presented an application of a depth-integrated SPH model to the debris flood which happened in Lo Wai (Hong Kong) in August 2005.

The main difficulties encountered by the authors in conducting the analysis are listed below.

(a) Modelling of overflowing water from the two activated weirs into a natural channel: the authors developed a method based on injecting SPH from a particle reservoir or pool, through a gate and into the two limbs of the natural stream. Suitable boundary conditions based on Riemann invariants were implemented.

(b) The rheological model chosen is a Bingham fluid, because of the composition of the entrained material. Bottom friction has been approximated using an improved version of the Pastor et al. (2004) model, based on using Tchebycheff polynomials as best approximations.

(c) As water erodes the natural streams, solid materials are entrained into the flow, causing its rheological properties to change. The authors have proposed simple laws to describe the dependence of the yield stress and the viscosity of a Bingham model on the solid concentration. 


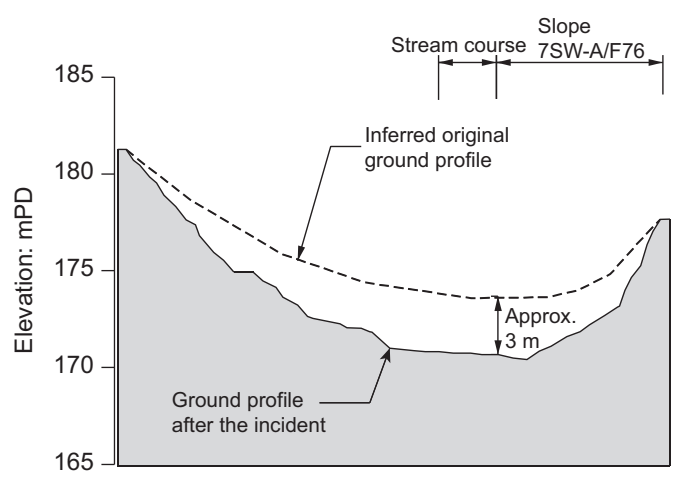

(a)

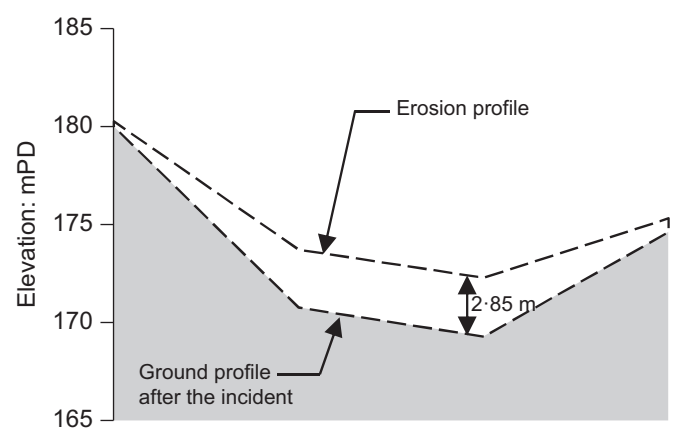

(b)

Fig. 19. Cross-section $\mathrm{Y}-\mathrm{Y}$ at approximate chainage $\mathrm{CH} 72$ before and after the incident: (a) observation compared against (b) computed results

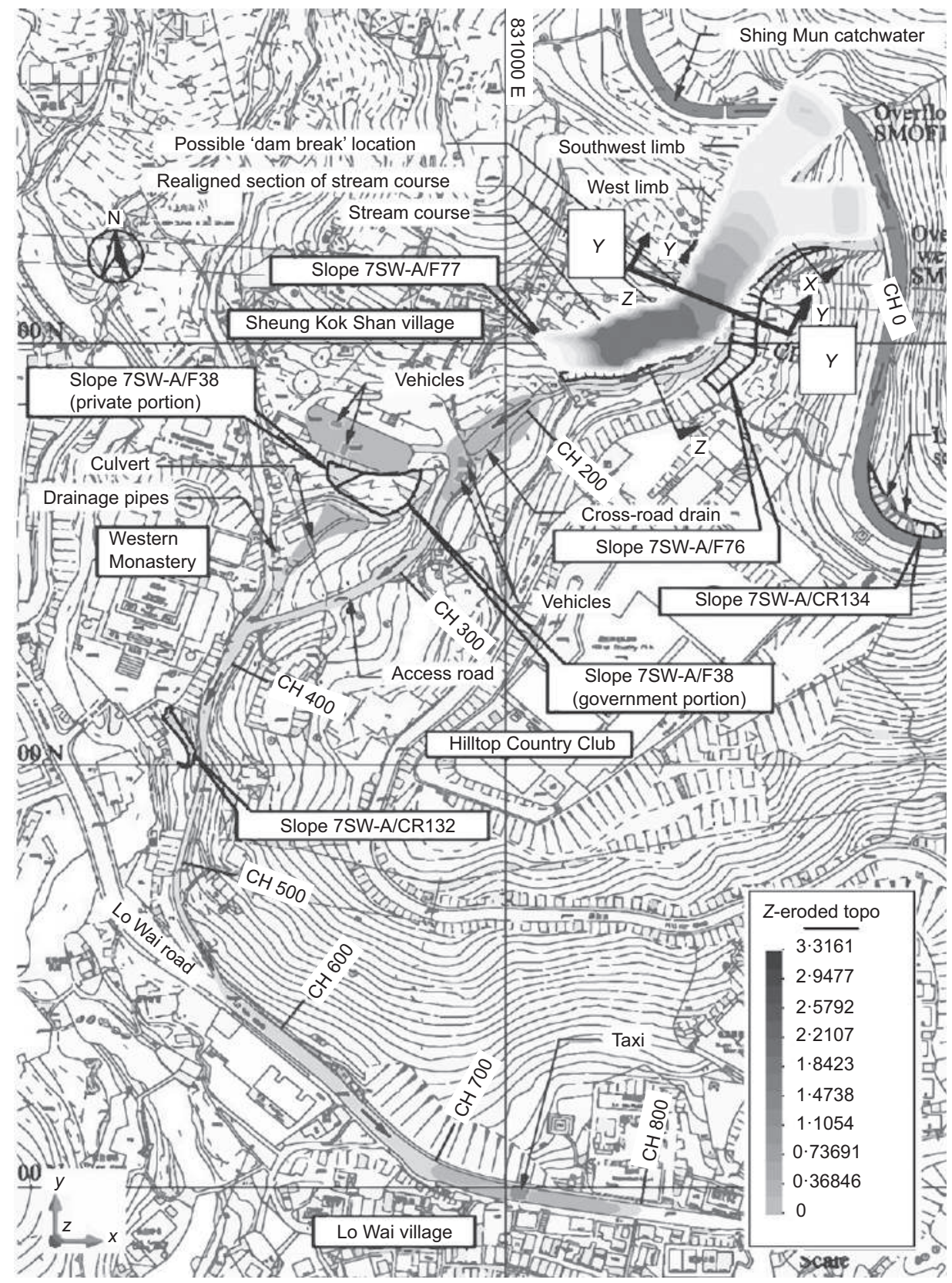

Fig. 20. Erosion depth over the terrain 


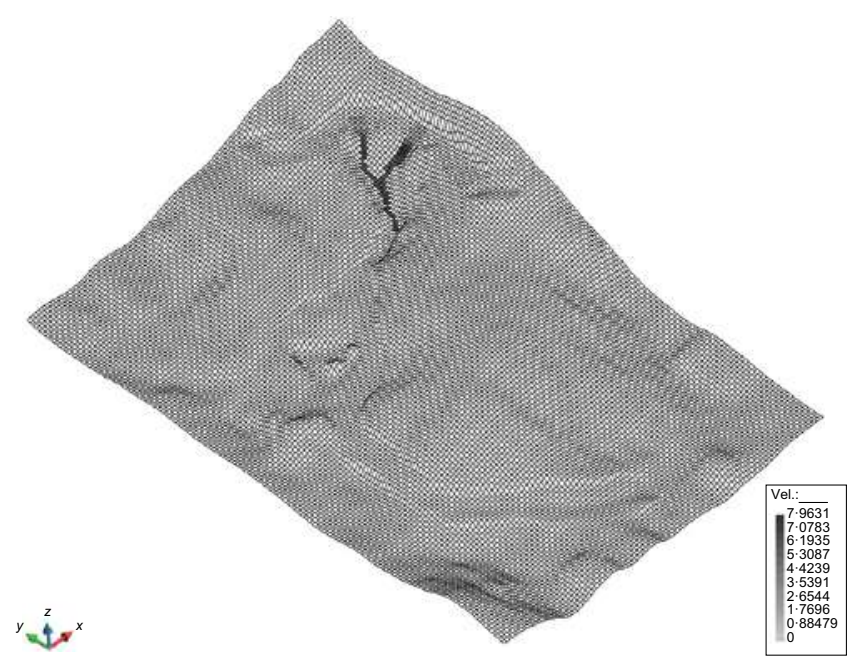

$t=20 \mathrm{~s}$

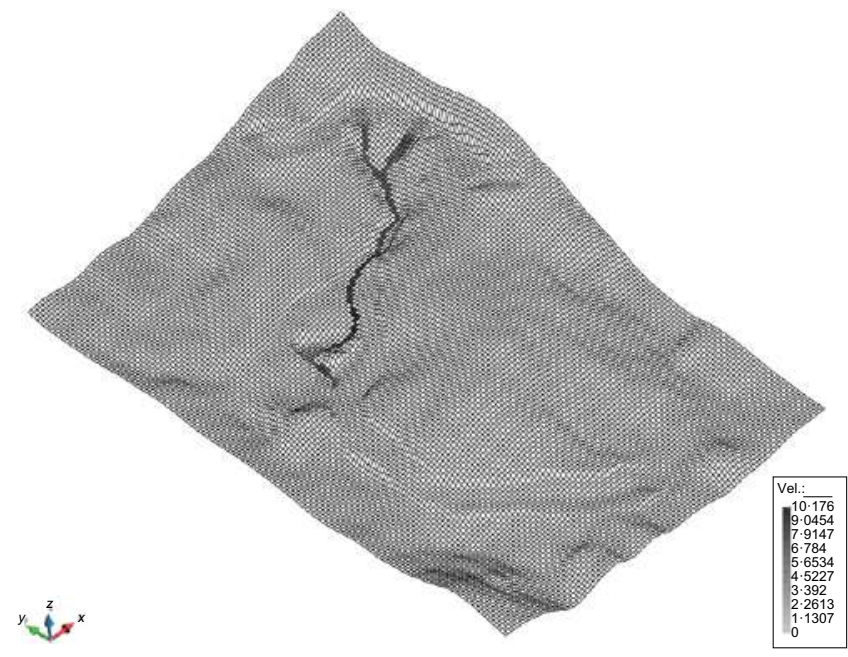

$t=60 \mathrm{~s}$

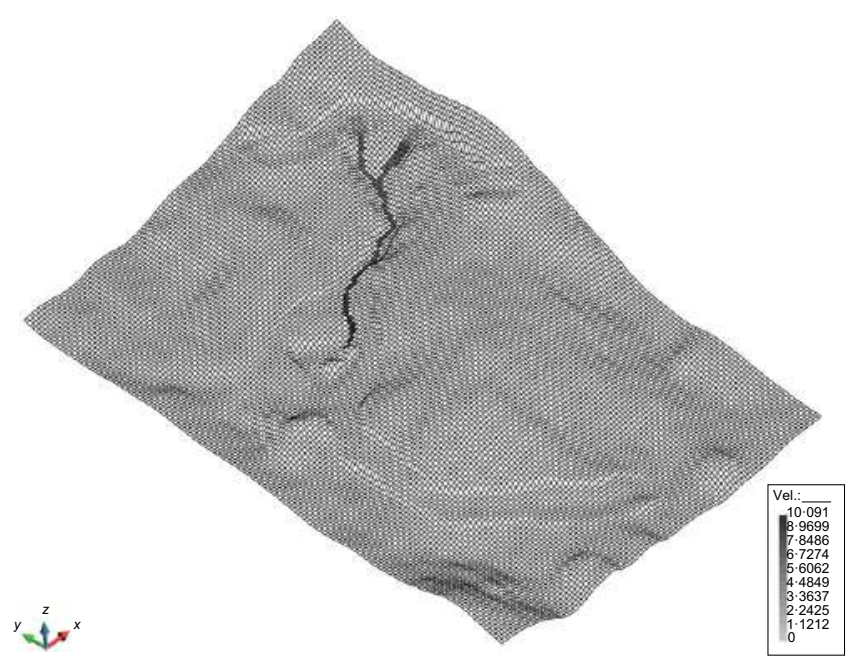

$t=40 \mathrm{~s}$

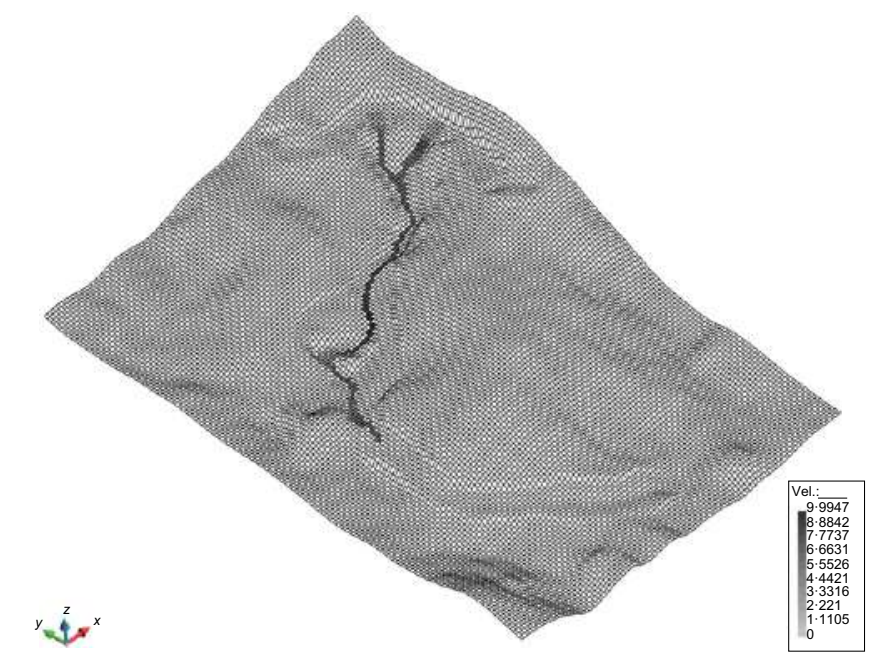

$t=80 \mathrm{~s}$

Fig. 21. Depth-averaged velocities at different times (continued on next page)

(d) Existing walls have been modelled using a zero normal velocity boundary condition for particles close to the walls.

The depth-integrated model was able to produce results of reasonable accuracy. It is important to notice that the rheological parameters were obtained by back-analysis.

The limitations of the proposed model are given below.

(a) The authors are aware that more complex mathematical models based on two sets of particles for water and soils will provide better results. They are currently working on extending the model to account for this.

(b) In order to improve the rheological model, and keep back-analysis to a minimum, rheometer tests on materials with different contents of water are needed.

(c) Singular elements such as small bridges, walls, buildings, culverts, drainage pipes and so on play an important role. More detailed topographical models are required to improve the model accuracy. If necessary, the flow in the proximity of those elements will be modelled using full 3D models.

(d) In the Lo Wai case, the catchwater channel was totally blocked by the landslides. In case of a partial blocking, 3D models for channel flow would have been necessary.

(e) Large elements such as fallen trees or big boulders have not been modelled in the analysis.

All limitations described above will be important research topics to address in future research work.

\section{ACKNOWLEDGEMENTS}

First, the authors gratefully acknowledge the economic support granted by: the Ministerio de Economía, Industria y Competitividad (MINECO), through the project ALAS (Advanced Modeling of Landslides, BIA2016-76253-P); the Postgraduate Research \& Practive Innovation Program of Jiangsu Province (KYZZ16_0282); the Special Fund for Public Welfare Industry of Ministry of Water Resources of China (grant no. 201501033); and the National Key Research and Development Program of China (grant no. 2016YFC0401601). Second, Mr Lin Chuan would like to express his gratitude to Professors Li Tongchun and Liu Xiaoqing, Hohai University, for the leave permission, funded by the China Scholarship Council. Third, the support of the Geotechnical Engineering Office, Civil Engineering and 


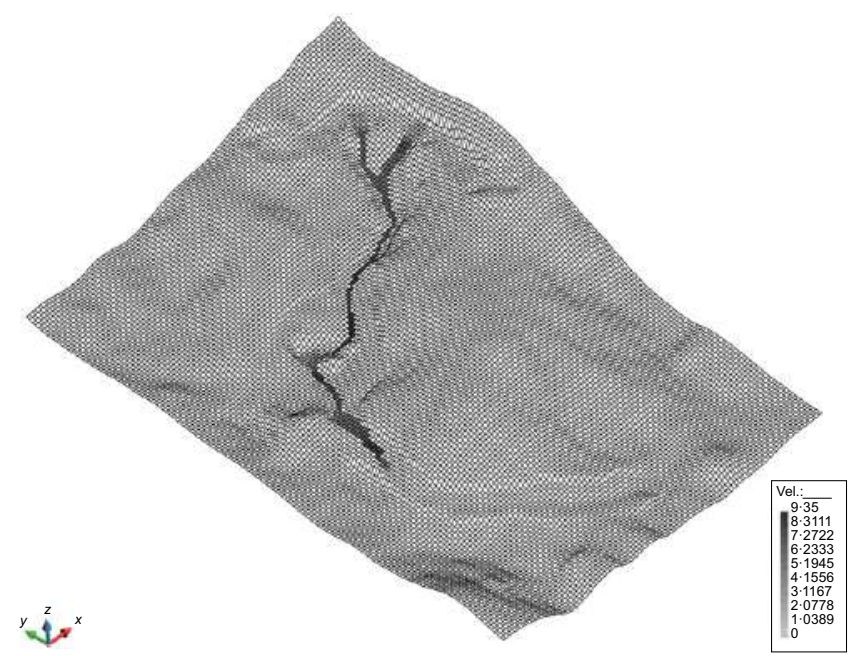

$t=100 \mathrm{~s}$

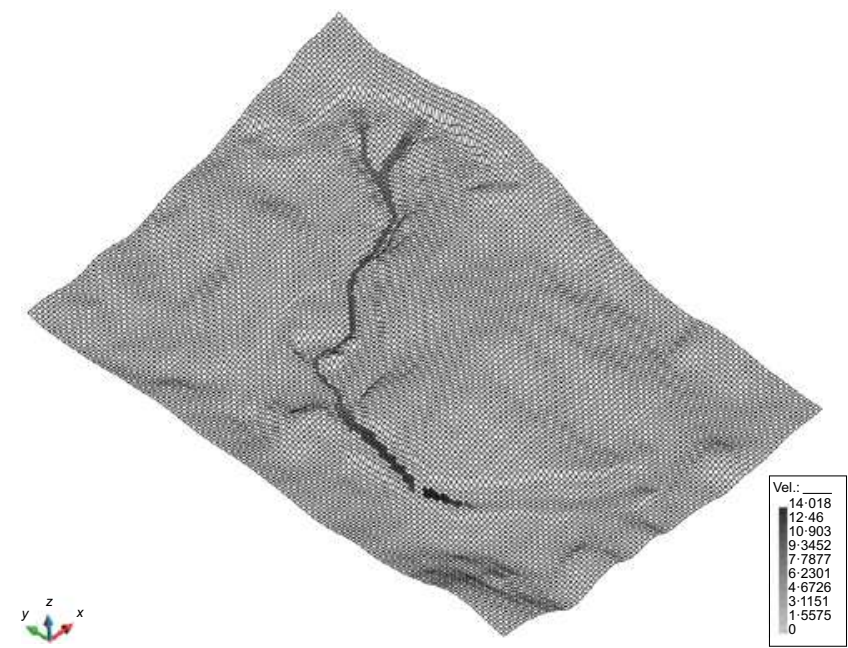

$t=140 \mathrm{~s}$

Fig. 21. Continued

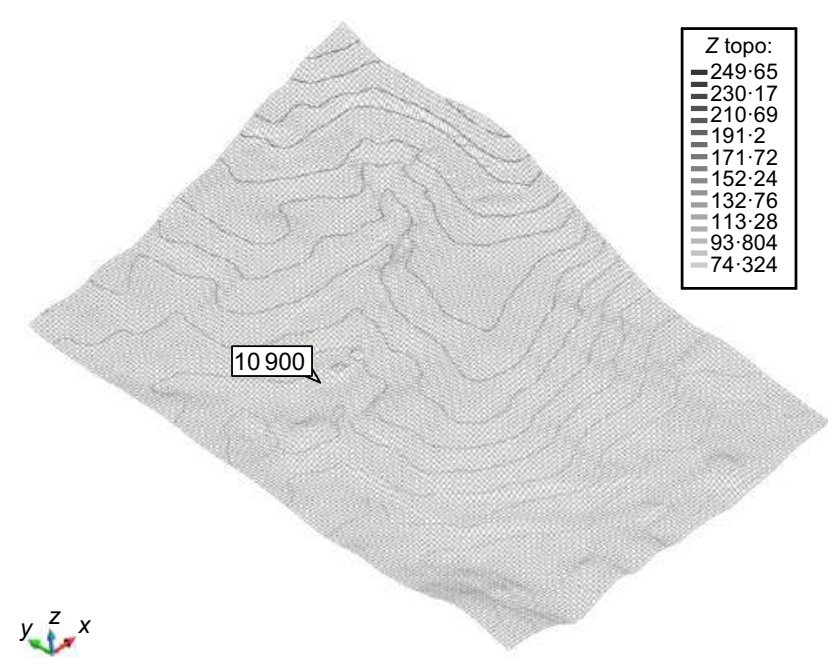

Fig. 22. Location of node 10900 of the digital terrain model grid

Development Department of the Government of the Hong Kong SAR in the provision of the digital terrain models and the valuable information for the Lo Wai (Hong Kong) debris flood case is gratefully acknowledged.

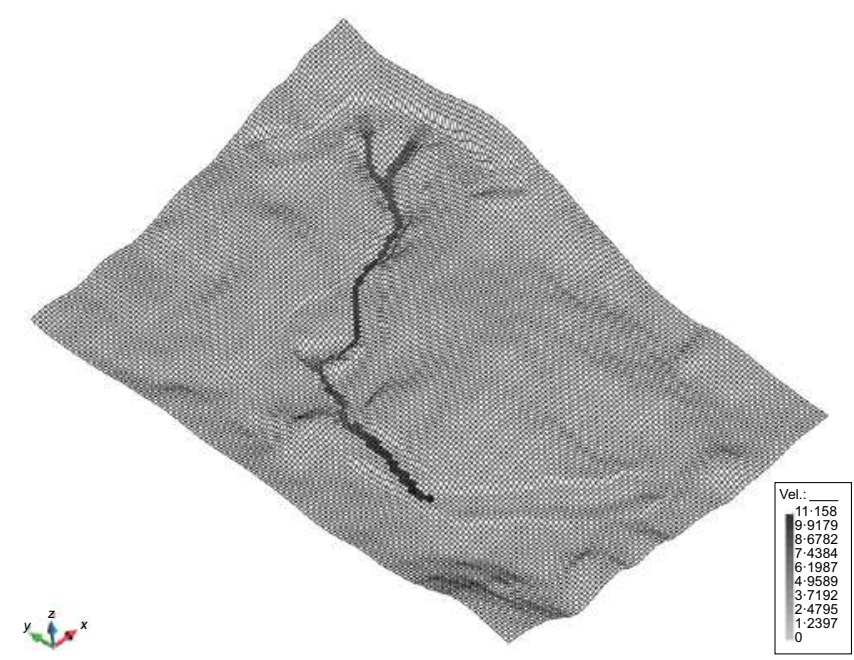

$t=120 \mathrm{~s}$

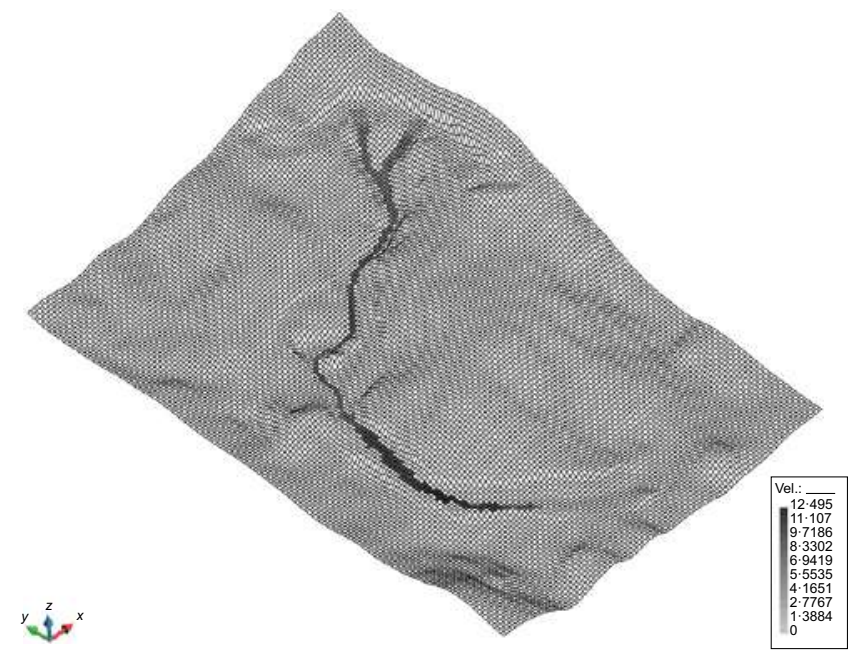

$t=160 \mathrm{~s}$

\section{APPENDIX. DESCRIPTION OF THE \\ MATHEMATICAL AND NUMERICAL MODELS \\ USED IN THE ANALYSIS}

The mathematical model is derived from the general 3D model describing movement of solid and pore fluid phases presented in Pastor et al. (2017), from which the depth-integrated equations have been obtained.

The reference system is sketched in Fig. 24. The coordinate axes are $\left\{x_{1}, x_{2}, x_{3}\right\} . Z$ denotes the basal surface elevation and $h$ is the depth of the flowing mass. For averaged magnitudes, over-bars are used. For instance

$$
\bar{\theta}=\frac{1}{h} \int_{Z}^{Z+h} \theta \mathrm{d} x_{3}
$$

Depth integration is performed taking into account Leibnitz's rule

$$
\int_{a}^{b} \frac{\partial}{\partial s} F(r, s) \mathrm{d} r=\frac{\partial}{\partial s} \int_{a}^{b} F(r, s) \mathrm{d} r-F(b, s) \frac{\partial b}{\partial s}+F(a, s) \frac{\partial a}{\partial s}
$$

The depth-integrated balance of mass equation is

$$
\frac{\overline{\mathrm{d}} h}{\mathrm{~d} t}+h \operatorname{div} \overline{\mathbf{v}}=e_{\mathrm{R}}
$$

where

$$
\frac{\mathrm{d}}{\mathrm{d} t}=\frac{\partial}{\partial t}+\bar{v}_{j} \frac{\partial}{\partial x_{j}} \quad j=1,2
$$




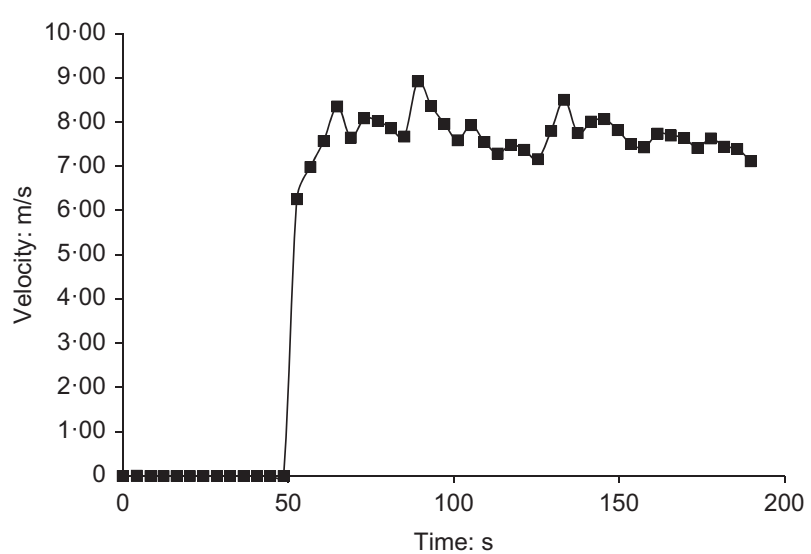

(a)

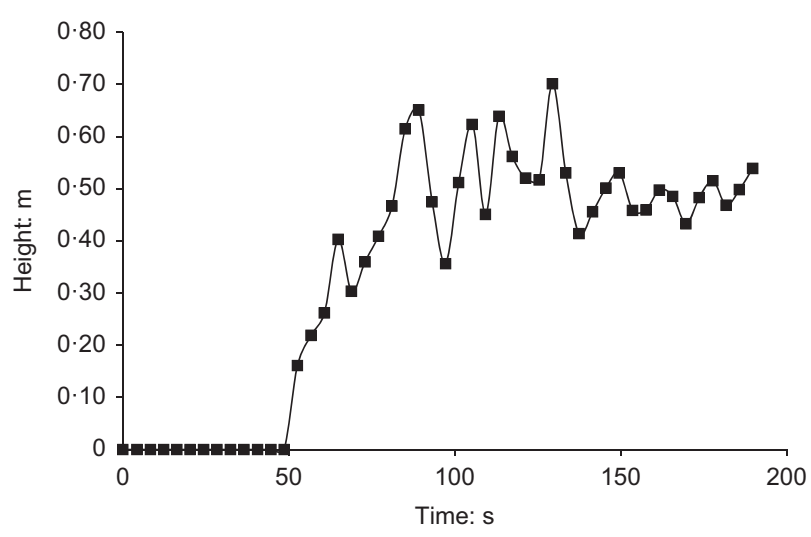

(b)

Fig. 23. Evolution of (a) velocity and (b) flow depth at node 10900

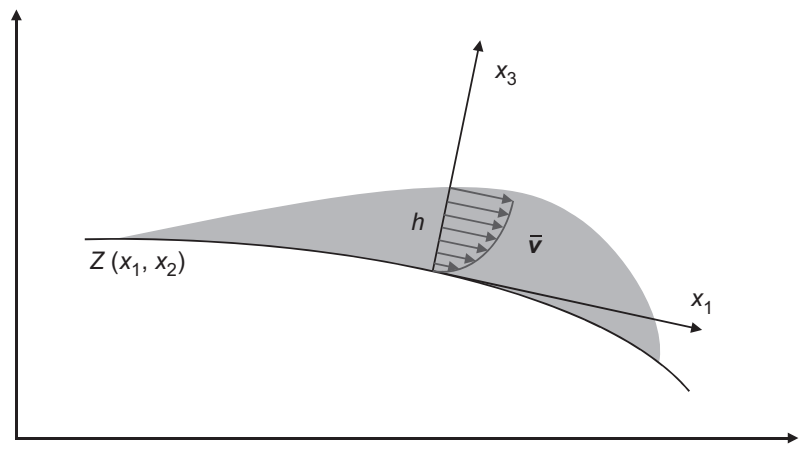

Fig. 24. Reference system, coordinates and notation used in the analysis

is the material derivative and $e_{\mathrm{R}}$ is the erosion rate, defined as the increment of height of the moving soil per unit time. There are laws, such as that proposed by Hutter et al. (2005), relating it to the depth-averaged velocity of the flowing material.

The balance of momentum is written as

$$
\rho h \frac{\mathrm{d} \overline{\boldsymbol{v}}}{\mathrm{d} t}=\operatorname{div}(h \overline{\boldsymbol{\sigma}})-\boldsymbol{\tau}_{b}+\rho \boldsymbol{b} h-\rho \overline{\boldsymbol{v}} e_{\mathrm{R}}
$$

where $\rho$ is the mixture density; $\overline{\boldsymbol{\sigma}}$ is the depth-integrated stresses; $\boldsymbol{\tau}_{\mathrm{b}}$ is the shear stresses at the bottom; and $\boldsymbol{b}$ is the gravity. If the stresses are assumed to be hydrostatic, the following equation is obtained

$$
\rho h \frac{\overline{\mathrm{d}} \overline{\boldsymbol{v}}}{\mathrm{d} t}=\operatorname{grad}\left\{\frac{1}{2} \rho h^{2} b_{3}\right\}-\boldsymbol{\tau}_{\mathrm{b}}+\rho \boldsymbol{b} h-\rho \overline{\boldsymbol{v}} e_{\mathrm{R}}
$$

In conclusion, the depth-integrated equations are (21) and (22), where the unknowns are the depth $h$ and the averaged velocity $\overline{\boldsymbol{v}}$.
The above equations have been discretised using the SPH method, which is based on the identity

$$
\phi(x)=\int_{\Omega} \phi\left(x^{\prime}\right) \delta\left(x^{\prime}-x\right) \mathrm{d} x^{\prime}
$$

where $\delta\left(x^{\prime}-x\right)$ is the Dirac's delta function centred at $x$.

The delta function can be approximated by a weighting function $W(x, h)$ fulfilling

$$
\lim _{h \rightarrow 0} W\left(x^{\prime}-x, \underline{h}\right)=\delta(x)
$$

where $h$ is a parameter describing its decay.

The function $\phi(x)$ is then approximated as

$$
\langle\phi(x)\rangle=\int_{\Omega} \phi\left(x^{\prime}\right) W^{\prime}\left(x^{\prime}-x, \underline{h}\right) \mathrm{d} x^{\prime}
$$

The weighting function or kernel $W(x, h)$ is a symmetric function of $\left(x^{\prime}-x, \underline{h}\right)$, which is positive and has compact support fulfilling the condition

$$
\lim _{h \rightarrow 0} W\left(x^{\prime}-x, \underline{h}\right)=\delta(x)
$$

Of all kernels proposed in the past, the cubic spline introduced by Monaghan (Monaghan \& Gingold, 1983; Monaghan \& Lattanzio, 1985) is used here.

Concerning the integral representation of the derivatives in $\mathrm{SPH}$, there is the expression

$$
\left\langle\phi^{\prime}(x)\right\rangle=\int_{\Omega} \phi^{\prime}\left(x^{\prime}\right) W\left(x^{\prime}-x, \underline{h}\right) \mathrm{d} x^{\prime}
$$
in

This expression is integrated by parts - in 1D problems - resulting

$$
\left\langle\phi^{\prime}(x)\right\rangle=-\int_{\Omega} \phi\left(x^{\prime}\right) W\left(x^{\prime}-x, \underline{h}\right) \mathrm{d} x^{\prime}
$$

Some differential operators of interest are approximated as

$$
\begin{aligned}
& \langle\operatorname{grad} \phi(x)\rangle=-\int_{\Omega} \phi\left(x^{\prime}\right) \frac{1}{h} W^{\prime} \frac{x^{\prime}-x}{r} \mathrm{~d} \Omega \quad \text { with } r=\left|x^{\prime}-x\right| \\
& \langle\operatorname{div} \boldsymbol{u}(x)\rangle=-\int_{\Omega} \boldsymbol{u}\left(x^{\prime}\right) \operatorname{grad} W \mathrm{~d} \Omega=-\int_{\Omega} \frac{1}{h} W^{\prime} \frac{\boldsymbol{u}\left(x^{\prime}\right) \cdot\left(x^{\prime}-x\right)}{r} \mathrm{~d} \Omega \\
& \langle\operatorname{div} \boldsymbol{\sigma}(x)\rangle=-\int_{\Omega} \boldsymbol{\sigma} \cdot \operatorname{grad} W \mathrm{~d} \Omega=-\int_{\Omega} \frac{1}{h} W^{\prime} \frac{\boldsymbol{\sigma} \cdot\left(x^{\prime}-x\right)}{r} \mathrm{~d} \Omega
\end{aligned}
$$

In $\mathrm{SPH}$, the information is stored in a discrete manner using particles or nodes.

A set of particles or nodes labelled with indices $K=1 \ldots N$ is therefore introduced. Of course, the level of approximation will depend on how these nodes are spaced and on their location. The classical finite-element strategy of having more nodes in those zones where larger gradients are expected can be applied here.

If the approximation of a function is considered, as the information concerning the function is only available at a set of $N$ nodes, the integral could be evaluated using a numerical integration technique leading to

$$
\phi_{I}=\left\langle\phi\left(x_{I}\right)\right\rangle_{h}=\sum_{J=1}^{N} \phi\left(x_{J}\right) W\left(x_{J}-x_{I}, \underline{h}\right) \Omega_{J}
$$

where the sub-index ' $h$ ' has been used to denote the discrete approximation smoothing length. The weights of the integration formula are $\Omega_{J}=m_{J} / \rho_{J}$, with $\Omega_{J}, m_{J}$ and $\rho_{J}$ being the volume, mass and densities associated with node $J$. In order to simplify the notation, $\phi_{I}$ is introduced, defined as

$$
\phi_{I}=\left\langle\phi\left(x_{I}\right)\right\rangle_{h}=\sum_{J=1}^{N} \phi\left(x_{J}\right) W\left(x_{J}-x_{I}, \underline{h}\right) \Omega_{J}
$$


If it is taken into account that the kernel function has local support - that is, it is zero when the summation extends only to the set of $N h$ points which fulfil this condition

$$
\phi_{I}=\left\langle\phi\left(x_{I}\right)\right\rangle_{h}=\sum_{J=1}^{N h} \phi\left(x_{J}\right) W\left(x_{J}-x_{I}, \underline{h}\right) \Omega_{J}
$$

which is a form commonly used in SPH. In the case where the function $\phi$ is chosen to represent the density, the following expression will be obtained

$$
\rho_{I}=\sum_{J=1}^{N h} \rho_{J} W_{I J} \frac{m_{J}}{\rho_{J}}=\sum_{J=1}^{n} W_{I J} m_{J}
$$

with $W_{I J}=W\left(x_{J}-x_{I}, \underline{h}\right)$.

If the $2 \mathrm{D}$ area associated with a node $I$ is $\Omega_{I}$, a fictitious volume $m_{I}$ with dimensions $L^{3}$ will be introduced moving with this node

$$
m_{I}=\Omega_{I} h_{I}
$$

From here, the balance of mass and momentum equations are discretised as

$$
\frac{\overline{\mathrm{d}} h_{I}}{\mathrm{~d} t}=\sum_{J} m_{J} v_{I J} \operatorname{grad} W_{I J}+\left\langle\bar{n} e_{\mathrm{R}}\right\rangle_{I}
$$

where $v_{I J}=v_{I}-v_{J}$ has been introduced.

Alternatively, instead of using the balance of mass equation, it is possible to obtain the height once the position of the nodes is known as

$$
\begin{aligned}
h_{I} & =\left\langle h\left(x_{I}\right)\right\rangle \\
& =\sum_{J} h_{J} \Omega_{J} W_{I J} \\
& =\sum_{J} m_{J} W_{I J}
\end{aligned}
$$

The height can be normalised, which allows the approximation close to the boundary nodes to be improved

$$
h_{I}=\frac{\sum_{J} m_{J} W_{I J}}{\sum_{J}\left(m_{J} / h_{J}\right) W_{I J}}
$$

The discretised balance of the linear momentum equation is

$$
\begin{aligned}
& \rho_{I} h_{I} \frac{\overline{\mathrm{d}}}{\mathrm{d} t} \bar{v}_{I}=-\rho \operatorname{grad}\{P\}+\boldsymbol{\tau}_{\mathrm{b}}+\rho h \boldsymbol{b}-\rho \overline{\boldsymbol{v}} e_{\mathrm{R}} \\
& P=-\frac{1}{2} h^{2} b_{3}
\end{aligned}
$$

Regarding the gradient, it has been discretised as

$$
\begin{aligned}
\frac{\overline{\mathrm{d}}}{\mathrm{d} t} \bar{v}_{I}= & \sum_{J} m_{J}\left(\frac{P_{I}}{h_{I}^{2}}+\frac{P_{J}}{h_{J}^{2}}\right) \operatorname{grad} W_{I J} \\
& +\frac{1}{\rho_{\alpha} h_{\alpha I}} \boldsymbol{\tau}_{b I}^{(\alpha)}+\boldsymbol{b}-\frac{1}{h_{I}} \overline{\boldsymbol{v}} e_{\mathrm{R}}
\end{aligned}
$$

The scheme is explicit, requiring the use of a time step limit given by the Courant-Friedrichs-Lewy (CFL) condition.

As the particles move relatively to each other, it is necessary to update the smoothing length, $\underline{h}$. Here, the variable smoothing length formula has been used

$$
h_{I} \underline{h}_{\mathrm{SMLI}}^{\mathrm{NDIM}}=\mathrm{const}
$$

where $\mathrm{h}_{\mathrm{SML} I}^{\mathrm{NDIM}}$ denotes the smoothing length at node I, NDIM being the number of dimension.

The algorithm is explicit, and less accurate than the approach proposed by Bonet et al. (2004), where both the mass conservation and the momentum equations were solved using a Newton-Raphson algorithm.

The resulting discretised equations are ordinary differential equations which can be integrated in time using a scheme such as 'leap frog' or Runge-Kutta (second or fourth order).

\section{NOTATION}

a non-dimensional parameter in Bingham fluids $\left(a=\mu \bar{v} / h \tau_{y}\right)$

b gravity

$b_{i} \quad$ component of body forces along $X_{i}$

$C$ evolution constant in function $f(s)$

$E_{\mathrm{s}}$ erosion coefficient, $E_{\mathrm{s}}=\ln \left(V_{\mathrm{f}} / V_{0}\right) /$ distance

$e_{\mathrm{R}}$ erosion rate

$F \quad$ slide Froude number; $F=V_{\mathrm{s}} /(g h)^{1 / 2}$

$g$ norm of gravitational acceleration: $g=9 \cdot 81 \mathrm{~m} / \mathrm{s}^{2}$

$h$ depth of flowslide

$h_{\text {SMLI }}^{\text {NDIM }}$ smoothing length at node I

$\bar{h}(t)$ hydrogram

$m_{\mathrm{I}}$ fictitious volume

$m_{\mathrm{s}}$ mass of soil particles

$m_{\mathrm{w}} \quad$ mass of water particles

$n$ porosity

$p$ hydrostatic pressure

$p_{2}(\xi)$ second-order polynomial

$p_{3}(\xi)$ third-order polynomial

$p_{\mathrm{w}}$ pore pressure

$Q$ mixed volumetric stiffness of solid grains and pore fluid

$\boldsymbol{R}$ interaction forces between phases

$R^{(2)^{*}} \quad$ Riemann invariant

$s \quad$ volume fraction of soil

$\bar{v}$ averaged velocity

$v_{\mathrm{S}} \quad$ velocity of solid particle

$v_{\mathrm{w}} \quad$ velocities of water particle

$Z$ terrain elevation

\section{REFERENCES}

Ata, R. \& Soulaïmani, A. (2005). A stabilized SPH method for inviscid shallow water flows. Int. J. Numer. Methods Fluids 47, No. 2, 139-159.

Balmforth, N. J. \& Liu, J. J. (2004). Roll waves in mud. J. Fluid Mech. 519, 33-54.

Bloor, D. J. (2011). Engineering geology and the assessment of channelised debris-flows: a Hong Kong case study. MSc thesis, University of Hong Kong, Hong Kong, PR China.

Bonet, J., Kulasegaram, S., Rodriguez-Paz, M. X. \& Profit, M. (2004). Variational formulation for the smooth particle hydrodynamics (SPH) simulation of fluid and solid problems. Comput. Methods Appl. Mech. Engng 193, No. 12, 1245-1256.

Brezzi, L., Bossi, G., Gabrieli, F., Marcato, G., Pastorand, M. \& Cola, S. (2016). A new data assimilation procedure to develop a debris flow run-out model. Landslides 13, No. 5, 1083-1096.

Calvello, M. \& Finno, R. J. (2004). Selecting parameters to optimize in model calibration by inverse analysis. Comput. Geotech. 31, No. 5, 411-425.

Chen, C. H., Lin, Y. T., Chung, H. R., Hsieh, T. Y., Yang, J. C. \& $\mathrm{Lu}$, J. Y. (2018). Modelling of hyperconcentrated flow in steep-sloped channels. J. Hydraul. Res. 56, No. 3, 380-398.

Cheong, H. F. (1991). Discharge coefficient of lateral diversion from trapezoidal channel. J. Irrig. Drainage Engng 117, No. 4, 461-475.

Costa, J. E. (1988). Rheologic, geomorphic, and sedimentologic differentiation of water floods, hyperconcentrated flows, and debris flows. In Flood geomorphology (eds V. R. Baker, R. C. Kochel and P. C. Patton), pp. 113-122. New York, NY, USA: John Wiley \& Sons.

De Campos, T. M. P. \& Galindo, M. S. V. (2016). Evaluation of the viscosity of tropical soils for debris flow analysis: a new approach. Géotechnique 66, No. 7, 533-545, https://doi.org/10. 1680/jgeot.15.P.080.

Dikau, R., Brunsden, D., Schrott, L. \& Ibsen, M. L. (1996). Landslide recognition: identification, movement, and causes. New York, NY, USA: Elsevier.

Frank, F., McArdell, B. W., Oggier, N., Baer, P., Christen, M. \& Vieli, A. (2017). Debris-flow modeling at Meretschibach and Bondasca catchments, Switzerland: sensitivity testing of field-data-based entrainment model. Nat. Hazards Earth Syst. Sci. 17, No. 5, 801 . 
Fread, D. L. (1988). The NWS DAMBRK model: theoretical background and user documentation, HRL-258. Silver Spring, MD, USA: Hydrological Research Laboratory, National Weather Service.

Gingold, R. A. \& Monaghan, J. J. (1977). Smoothed particle hydrodynamics: theory and application to non-spherical stars. Mon. Not. R. Astr. Soc. 181, No. 3, 375-389.

Ho, K., Lau, T. \& Lau, J. (2009). Forensic landslide investigations in Hong Kong. Proc. Instn Civ. Engrs - Civ. Engng 162, No. 5, 44-51, https://doi.org/10.1680/cien.2009.162.5.44.

Hungr, O. (2005). Classification and terminology. In Debris-flow hazards and related phenomena (eds M. Jakob and O. Hungr), pp. 9-23. Chichester, UK: Springer-Praxis.

Hungr, O. \& Evans, S. G. (2004). Entrainment of debris in rock avalanches: an analysis of a long run-out mechanism. Geol. Soc. Am. Bull. 116, No. 9-10, 1240-1252.

Hungr, O., McDougall, S. \& Bovis, M. (2005). Entrainment of material by debris flows. In Debris-flow hazards and related phenomena (eds M. Jakob and O. Hungr), pp. 135-158. Chichester, UK: Springer-Praxis.

Hutchinson, J. H. (1988). Morphological and geotechnical parameters of landslides in relation to geology and hydrogeology, landslides. In Proceedings of the 5th international symposium on landslides (ed. C. Bonnard), pp. 3-35. Rotterdam, the Netherlands: Balkema.

Hutter, K. \& Koch, T. (1991). Motion of a granular avalanche in an exponentially curved chute: experiments and theoretical predictions. Phil. Trans. R. Soc. Lond. A: Math., Phys. Engng Sci. 334, No. 1633, 93-138.

Hutter, K., Wang, Y. \& Pudasaini, S. P. (2005). The Savage-Hutter avalanche model: how far can it be pushed? Phil. Trans. R. Soc. Lond. A: Math., Phys. Engng Sci. 363, No. 1832, 1507-1528.

Iverson, R. M., Logan, M., Denlinger, R. P. \& Lahusen, R. G. (2005). Transformation of water floods to debris flows: largescale experiments. Geol. Soc. Am. Abstr. 37, No. 7, 35.

Jeyapalan, J. K., Duncan, J. M. \& Seed, H. B. (1983). Investigation of flow failures of tailing dams. J. Geotech. Eng. 109, No. 2, 172-189.

Komatina, D. \& Jovanovic, M. (1997). Experimental study of steady and unsteady free surface flows with water-clay mixtures. J. Hydraul. Res. 35, No. 5, 579-590.

Laigle, D. \& Coussot, P. (1997). Numerical modeling of mudflows. J. Hydraul. Engng 123, No. 7, 617-623.

Lastiwka, M., Quinlan, N. \& Basa, M. (2005). Adaptive particle distribution for smoothed particle hydrodynamics. Int. J. Numer. Methods Fluids 47, No. 10-11, 1403-1409.

Li, W., Su, Z., van Maren, D. S., Wang, Z. \& de Vriend, H. J. (2017). Mechanisms of hyperconcentrated flood propagation in a dynamic channel-floodplain system. Adv. Wat. Resour. 107, 470-489.

Libersky, L. D., Petschek, A. G., Carney, T. C., Hipp, J. R. \& Allahdadi, F. A. (1993). High strain Lagrangian hydrodynamics: a three-dimensional SPH code for dynamic material response. J. Comput. Phys. 109, No. 1, 67-75.

Liu, G. R. \& Liu, M. B. (2003). Smoothed particle hydrodynamics: a meshfree particle method. Singapore: World Scientific Publishing.

Lucy, L. B. (1977). A numerical approach to the testing of the fission hypothesis. Astr. J. 82, 1013-1024.

McDougall, S. \& Hungr, O. (2004). A model for the analysis of rapid landslide motion across three-dimensional terrain. Can. Geotech. J. 41, No. 6, 1084-1097.

MGS (Maunsell Geotechnical Services Limited) (2006). Review of the 20 August 2005 debris flood at Lo Wai, Tsuen Wan, Landslide study report LSR 5/2006. Hong Kong, China: Landslip Preventive Measures Division 1, Geotechnical Engineering Office of Hong Kong.

Monaghan, J. J. (1982). Why particle methods work. SIAM J. Sci. Statist. Comput. 3, No. 4, 422-433.

Monaghan, J. J. \& Gingold, R. A. (1983). Shock simulation by the particle method SPH. J. Comput. Phys. 52, No. 2, 374-389.

Monaghan, J. J. \& Lattanzio, J. C. (1985). A refined particle method for astrophysical problems. Astr. Astrophys. 149, No. 1, $135-143$.
Monaghan, J. J., Cas, R. A. F., Kos, A. M. \& Hallworth, M. (1999). Gravity currents descending a ramp in a stratified tank. J. Fluid Mech. 379, 39-69.

O’Brien, J. S. \& Julien, P. Y. (1988). Laboratory analysis of mudflow properties. J. Hydraul. Engng 114, No. 8, 877-887.

O'Brien, J. S., Julien, P. Y. \& Fullerton, W. T. (1993). Two-dimensional water flood and mudflow simulation. J. Hydraul. Engng 119, No. 2, 244-261.

Pastor, M., Quecedo, M., González, E., Herreros, M. I., Merodo, J. F. \& Mira, P. (2004). Simple approximation to bottom friction for Bingham fluid depth integrated models. J. Hydraul. Engng 130, No. 2, 149-155.

Pastor, M., Blanc, T., Pastor, M. J., Sanchez, M., Haddad, B., Mira, P., Fernandez Merodo, J. A., Herreros, I. \& Drempetic, V. (2007). A SPH depth integrated model with pore pressure coupling for fast landslides and related phenomena. In Proceedings of the 2007 international forum on landslide disaster management (eds K. Ho and V. Li), vol. II, pp. 987-1014. Hong Kong, China: Geotechnical Division, Hong Kong Institution of Engineers.

Pastor, M., Blanc, T. \& Pastor, M. J. (2009a). A depth-integrated viscoplastic model for dilatant saturated cohesive-frictional fluidized mixtures: application to fast catastrophic landslides. J. Non-Newtonian Fluid Mech. 158, No. 1, 142-153.

Pastor, M., Haddad, B., Sorbino, G., Cuomo, S. \& Drempetic, V. (2009b). A depth-integrated, coupled SPH model for flow-like landslides and related phenomena. Int. J. Numer. Analyt. Methods Geomech. 33, No. 2, 143-172.

Pastor, M., Yague, A., Stickle, M. M., Manzanal, D. \& Mira, P. (2017). A two-phase SPH model for debris flow propagation. Int. J. Numer. Analyt. Methods Geomech. 42 , No. 3, 418-448.

Peraire, J., Zienkiewicz, O. C. \& Morgan, K. (1986). Shallow water problems: a general explicit formulation. Int. J. Numer. Methods Engng 22, No. 3, 547-574.

Pierson, T. C. \& Costa, J. E. (1987). A rheologic classification of subaerial sediment-water flows. In Debris flows/avalanches (eds J. E. Costa and G. F. Wieczorek), GSA Reviews in Engineering Geology, vol. 7, pp. 1-12. Boulder, CO, USA: Geological Society of America.

Pirulli, M. \& Pastor, M. (2012). Numerical study on the entrainment of bed material into rapid landslides. Géotechnique 62, No. 11, 959-972, https://doi.org/10.1680/geot.10.P.074.

Pitman, E. B. \& Le, L. (2005). A two-fluid model for avalanche and debris flows. Phil. Trans. R. Soc. Lond. A: Math., Phys. Engng Sci. 363, No. 1832, 1573-1601.

Pudasaini, S. P. \& Hutter, K. (2007). Avalanche dynamics: dynamics of rapid flows of dense granular avalanches. Berlin, Germany: Springer Science \& Business Media.

Randles, P. W. \& Libersky, L. D. (1996). Smoothed particle hydrodynamics: some recent improvements and applications. Comput. Methods Appl. Mech. Engng 139, No. 1-4, 375-408.

Rickenmann, D. (1991). Hyperconcentrated flow and sediment transport at steep slopes. J. Hydraul. Engng 117, No. 11, 1419-1439.

Rodriguez-Paz, M. \& Bonet, J. (2005). A corrected smooth particle hydrodynamics formulation of the shallow-water equations. Comput. Structs 83, No. 17, 1396-1410.

Savage, S. B. \& Hutter, K. (1991). The dynamics of avalanches of granular materials from initiation to runout. Part I: analysis. Acta Mechanica 86, No. 1, 201-223.

Vacondio, R., Rogers, B. D., Stansby, P. K. \& Mignosa, P. (2011). SPH modeling of shallow flow with open boundaries for practical flood simulation. J. Hydraul. Engng 138, No. 6, 530-541.

Vacondio, R., Rogers, B. D., Stansby, P. K. \& Mignosa, P. (2013a). Shallow water SPH for flooding with dynamic particle coalescing and splitting. Adv. Wat. Resour. 58, 10-23.

Vacondio, R., Rogers, B. D., Stansby, P. K., Mignosa, P. \& Feldman, J. (2013b). Variable resolution for SPH: a dynamic particle coalescing and splitting scheme. Comput. Methods Appl. Mech. and Engng 256, 132-148.

Vacondio, R. E. N. A. T. O., Mignosa, P. \& Pagani, S. (2013c). 3D SPH numerical simulation of the wave generated by the Vajont rockslide. Adv. Wat. Resour. 59, 146-156. 
Xia, X., Liang, Q., Pastor, M., Zou, W. \& Zhuang, Y. F. (2013). Balancing the source terms in a SPH model for solving the shallow water equations. Adv. Wat. Resour. 59, 25-38.

Yumuang, S. (2006). 2001 debris flow and debris flood in Nam Ko area, Phetchabun province, central Thailand. Environ. Geol. 51, No. $4,545-564$.
Zhu, Y. \& Fox, P. J. (2001). Smoothed particle hydrodynamics model for diffusion through porous media. Transp. Porous Media 43, No. 3, 441-471.

Zienkiewicz, O. C., Chan, A. H. C., Pastor, M., Schrefler, B. A. \& Shiomi, T. (1999). Computational geomechanics with special reference to earthquake engineering, pp. 105-110. Chichester, UK: Wiley. 